\title{
FEA Analysis of AP-0 Target Hall Collection Lens (Current Design)
}

\author{
P. G. Hurh \& Z. Tang
}

(6/22/01)

\section{INTRODUCTION}

The AP-0 Target Hall Collection Lens is a pulsed device which focuses anti-protons just downstream of the Target. Since the angles at which the anti-protons depart the Target can be quite large, a very high focusing strength is required to maximize anti-proton capture into the downstream Debuncher Ring. The current design of the Collection Lens was designed to operate with a focusing gradient of $1,000 \mathrm{~T} / \mathrm{m}$. However, multiple failures of early devices resulted in lowering the normal operating gradient to about $750 \mathrm{~T} / \mathrm{m}$. At this gradient, the Lens design fares much better, lasting several million pulses, but ultimately still fails. A Finite Element Analysis (FEA) has been performed on this Collection Lens design to help determine the cause and/or nature of the failures.

The Collection Lens' magnetic field is created by passing high current through a central conductor cylinder. A uniform current distribution through the cylinder will create a tangential or azimuthal magnetic field that varies linearly from zero at the center of the cylinder to a maximum at the outer surface of the cylinder. Anti-proton particles passing through this cylinder (along the longitudinal direction) will see an inward focusing kick back toward the center of the cylinder proportional to the magnetic field strength. For the current Lens design a gradient of $1,000 \mathrm{~T} / \mathrm{m}$ requires a current of about 580,000 amps. Since the DC power and cooling requirements would be prohibitive, the Lens is operated in a pulsed mode. Each pulse is half sine wave in shape with a pulse duration of about 350 microseconds. Because of the skin effect, the most uniform current density actually occurs about two-thirds of the way through the pulse. This means that the maximum current of the pulse is actually higher than that required in the DC case (about 670,000 amps).

Since the beam must pass through the central conductor cylinder it must be made of a conducting material that is also very 'transparent' to the beam. For the Collection Lens, this material is lithium (Li). The central conductor cylinder is a lithium cylinder $1 \mathrm{~cm}$ in radius and about $14 \mathrm{~cm}$ long. Figure 1 shows this cylinder in a cross-section view of the Collection Lens. Surrounding the central cylinder is a jacket of titanium alloy (6Al-4V ELI) called the septum. The septum's purpose is to contain the lithium against various thermal and magnetic forces while allowing cooling (melting point of $\mathrm{Li}$ is $180.5^{\circ} \mathrm{C}$ ) by an annular water passage. The ends of the Li cylinder are bound by end windows made of beryllium (Be) 
and a thin titanium (ti) foil. The foil protects the Be from the corrosive effects of $\mathrm{Li}$ and the Be window provides the structural support. The two end windows sit in pockets in the ends of two larger steel cylinders or body halves. The body halves are separated from each other by ceramic spacers. The body halves, septum and end windows are connected to each other by nickel $(\mathrm{Ni})$ seals which preserve the boundary of the lithium conductor. Force required to make these seals is provided by eight Ti $6 \mathrm{Al}-4 \mathrm{~V}$ ELI tie rods which traverse the entire assembly. These tie rods also resist magnetic forces that attempt to separate the body halves during the current pulse. There are several insulating components that are used to isolate one side of the lens from the other and force the current through the central $\mathrm{Li}$ conductor.

The volumes of $\mathrm{Li}$ at each end of the central conductor cylinder outside the septum but inside the body halves are called buffer volumes. These buffer volumes serve two roles. One, they provide a low resistance current path to the end of the central conductor cylinder. Two, they provide a volume for Li to expand into during the current pulse. For the latter it is assumed that magnetic forces and thermal strains will force lithium from the central cylinder and into the buffer volumes during the current pulse.

There are several loads on the Lens that are developed during a current pulse. High magnetic loads act radially and longitudinally outward on the steel body halves and radially inward on the central conductor cylinder. This latter force on the Li cylinder is termed the magnetic pinch effect and could result in the separation of the Li from the septum inner wall. To prevent this from happening, the Li is actually pre-loaded when the Lens is filled. During the current pulse, ohmic losses heat the various components and create thermal strains. This, coupled with beam losses, create non-uniform displacements and therefore stresses in the Lens' components. Finally, the pre-loaded tie rods add yet another load to the Lens.

Since the geometry, materials, and loads are so complex and interdependent, an analysis should try to integrate all these aspects in one model if possible. ANSYS finite element code has been utilized in an attempt to do so. The results are hoped to shed light on why the current Collection Lens design fails at high gradient (short term) and low gradient (long term). The development of the model may also help pave the way for using similar models as design tools for future Collection Lens designs.

\section{DESCRIPTION OF ANSYS MODEL}

An ANSYS model was created to simulate the Lens by dividing the problem into three solutions, an electromagnetic (E-M) solution, a thermal solution, and a structural solution. The E-M solution models the transient magnetic response of the Lens through one current pulse. The 
thermal solution uses the results from the E-M solution to model the transient thermal response of the Lens between pulses (for many pulses). And the structural solution uses the results from both previous solutions to model the static structural behavior of the Lens at time points of interest. Figure 2 shows a schematic of how the three solutions interact. Because of the existing complexity of the problem, the analysis assumes that all material properties are constant with respect to temperature (see Section IV: Conclusions).

\section{A. Electro-Magnetic Solution}

In order to simplify the model, the E-M solution was simulated using the ANSYS thermal diffusion solver and making the necessary substitutions (see Appendix 2). Essentially this thermal simulation of the magnetic field takes advantage of the similarity of the magnetic field equation in cylindrical coordinates (axisymmetric) to the thermal diffusion equation in 2-D Cartesian coordinates. Thus a complicated three dimensional skin effect problem can be easily modeled as a two dimensional model within ANSYS. However, this simulation precludes the use of ANSYS to automatically iterate for temperature dependent material properties since the temperature degree of freedom is no longer temperature in the conventional sense. It also results in a singularity at nodes on the center axis (radius $=0$ ) because the radius appears in the denominator in most of the necessary substitutions.

The geometry of the model is simplified from the actual geometry to avoid unnecessary detail in the element mesh. Figure 3 shows the model geometry that is used for all three solutions. Material properties used for the analysis are shown in Table 1. Note that the saturation of the steel body was taken into account by manually iterating the permeability of each steel element at each load step.

The only loads for this portion of the simulation are the prescribed magnetic field strengths on the periphery of the model. In particular, the field at the boundary between 'legs' of the current loop. At these nodes, the magnetic field strengths are assigned at each step of the solution during the current pulse to correspond with the applied current (670 kA peak). For the E-M solution, the current pulse is divided into 12 steps, each with 20 sub-steps. An additional period of time equal in length to one pulse (350 microsecond) was also simulated to allow the magnetic fields to dissipate.

Results from the E-M solution consist of magnetic field strength distribution, current density distribution, and magnetic forces. The magnetic field results can be used to check for linearity of the gradient at the time of beam passage and as input for particle 
tracking analysis (MARS code). The current density results can be used as input for the thermal solution (ohmic heating). And the magnetic force results can be used as input in the structural solution.

\section{B. Thermal Solution}

The thermal solution is a transient conduction, axisymmetric simulation. The simulation models the time period between pulses ( 1.5 seconds) over several hundred pulses until quasi-static conditions are reached (temperatures cycle between constant values). Heat input is considered to take place instantaneously at each current pulse and heat output (cooling) is considered to take place continuously.

Loads for this solution include current density distribution, beam heating, and the various cooling boundary conditions. The current density distributions from the previous E-M solution are used to calculate the energy deposited by the current pulse. The beam heating loads are calculated using CASIM code assuming 5E 12 protons per pulse on Target. See Table 2 for CASIM output. Cooling 'loads' include septum cooling from the water circuit, convective cooling to surrounding air, and conduction through transformer fingers (see Table 3 for calculated heat transfer coefficients). Radiation elements between the septum and the body halves were also added to the element mesh for the thermal solution.

Results from the thermal solution are temperature distributions over time between pulses. These results are used directly to apply thermal strain to the structural solution at specific time points of interest.

\section{Structural Solution}

The structural solution is a static, axisymmetric model that simulates the behavior of the Lens structure under the different loading cases that occur at various time points of interest. Time points of interest include just before a current pulse, at the time of maximum current during a current pulse, and just after a current pulse. This solution is actually a superposition of two solutions, that of the initial conditions and that of the thermal/magnetic loading.

The initial condition solution itself is also a superposition of two solutions, that of the pressurized lithium volume and that of the Lens structure under pre-load and bolt loading. The pressurized lithium volume is created by fixing the lithium volume boundary conditions and applying a uniform temperature distribution which corresponds to approximately 2,000 psi stress in all directions. The pre-loaded Lens structure is created by applying a 2,000 psi 
pressure loading to the lithium volume boundaries and a load at the outside edges of the lens corresponding to the bolt pre-load $(57,000$ pounds). The superposition of these two solutions is the initial condition solution.

The thermal/magnetic loading solution consists of the nodal solution for the Lens model under specific load cases. For the load case just before and just after a current pulse, the only load is the temperature distribution results from the corresponding step of the transient thermal solution. For the load case at maximum current of a current pulse, the loads are the maximum magnetic forces from the E-M solution and the average of the temperature distributions results from before and after the current pulse. The superposition of each of these solutions with the initial condition solution is the final solution for each time point of interest.

Material properties for the structural solution are also shown in Table 1 . The low yield stress of the lithium (about $76 \mathrm{psi}$ ) is simulated by elastic-plastic behavior. Up to the yield point, the higher elastic modulus value is used. After the yield point the lower plastic modulus value is used. This effectively simulates the elastic/plastic deformation of the lithium.

Results from the structural solution consist of nodal displacements and all the various derived quantities from those displacements (stresses, strains).

\section{RESULTS}

\section{A. E-M Results}

Figures 4 through 8 show the E-M results. The magnetic field strength results confirm that approximately 10 Tesla field is achieved on the $\mathrm{Li}$ conductor surface for a peak current of $670 \mathrm{kA}$. Figure 8 shows the magnetic field strength vs radial distance in the $\mathrm{Li}$ core. The time of beam passage is sometime between steps 8 and 9 where the slope is most linear. Note that the anomalies in the curves near $r=0$ are due to forcing the solution to zero to avoid singularities.

\section{B. Thermal Results}

Figures 9 through 11 show the thermal results. Figure 9 shows how the lens responds to continuous pulsing from initial conditions. Note that the Li core temperature varies the most and comes up to quasi-static condition very quickly. Temperatures in the steel body are slower to respond, but still come up to quasi-static condition within 300 seconds. 
Figure 10 shows the temperature distribution both before and after a current pulse. Note that the temperature in the Li volume is well below melting (melting point of $\mathrm{Li}$ is $181^{\circ} \mathrm{C}$ ).

Figure 11 shows the temperature distribution across the Li core and Ti septum inner wall at various times after the pulse. Note that the temperature of the septum wall (greater than $1 \mathrm{~cm}$ ) actually increases just after the pulse as heat is drawn into it from the hotter Li volume.

\section{Structural Results}

Figures 12 through 42 show the results of the structural solution. Displacement of the Lens structure is relatively small compared to the lithium volume. It can be seen from Figures 16 through 18 that the lithium in the central conductor cylinder is squeezed by the magnetic pinch radially inward and axially outward toward the Be windows by as much as $2.91 \mathrm{E}-4 \mathrm{~m}$ (0.011 in). Much of this displacement is recovered after the magnetic pinch is removed (85\%), but a net displacement remains. By the time of the next pulse $(1.5 \mathrm{sec})$ this net displacement is also recovered. It is interesting to note that movement of lithium into the buffer volumes is not readily apparent.

Figures 19 through 21 show the equivalent stress (Von Mises) in the Lens before, during, and after a pulse. The highest stress of course occurs in the ceramic center insulator from the bolt pre-load. However, this is not a concern because of the high compressive strength of alumina ceramic. Of primary concern is the integrity of the septum. In this area we see that the stress varies from about $1.87 \mathrm{E} 8 \mathrm{~Pa}(27.1 \mathrm{ksi})$ before the pulse to $3.86 \mathrm{E} 8 \mathrm{~Pa}(56.0 \mathrm{ksi})$ at the peak of the pulse. This is well beneath the yield strength of the titanium alloy 6Al-4V ELI of $125 \mathrm{ksi}$. Of course with the pulsed nature of the loading, fatigue performance is of greater importance.

Since equivalent stress (Von Mises) is independent of load direction and fatigue endurance limit is dependent on load direction (tensile versus compressive), equivalent stress cannot be used to evaluate fatigue performance. Comparisons should be made using the actual directional stress if possible. Figures 22 through 30 show the stress in the Lens structure in each of the three coordinate axes directions before, during, and after a pulse. Positive $\mathrm{x}$ direction is radially outward (up in figures). Positive y direction is axially outward from the center of the Lens (left in figures). Positive $z$ is azimuthal or tangential (hoop; out of page in figures). Figures 28 through 30 show that the stress that dominates the equivalent stress in the septum is in the hoop direction ( $z$ direction). For the septum inner conductor tube, the hoop stress is used to calculate the cyclic load stresses shown in Table 4. 
The large compressive hoop stress in the septum inner conductor tube shown in Figure 29 during the pulse is due to the magnetic pinch effect on the lithium volume. In essence the lithium volume is pulling the titanium septum tube in during the magnetic pinch. However, since the tensile strength of lithium is very low (2 $\mathrm{ksi}$ ), it is unlikely that such large compressive stresses would be developed in the septum inner conductor tube. Instead the lithium at the boundary with the surrounding tube would tear or separate causing a void. Voids in this location could be detrimental to lens performance. In fact some evidence of the tensile stress in the lithium is seen in Figure 23 (stress in radial direction). However, because the element mesh is not very fine in this region, the effect is not pronounced (see Conclusions section). In any case, a conservative approach would be to use the large compressive stress when comparing to fatigue endurance limits.

Fatigue endurance limits for Ti 6Al-4V ELI vary with many factors including microstructure, surface finish, and temperature. Using a generally accepted constant life fatigue curve for annealed bar (source: R. Wood and R. Favor, Titanium Alloys Handbook, MCIC-HB-02, Batelle Columbus Laboratories, p 5-4:72-23) shown in Figure 43, the endurance limit for unnotched (1E7 cycles) is about $73 \mathrm{ksi}$; and for notched: $42 \mathrm{ksi}$. This is for an $\mathrm{R}$ value (minimum stress/maximum stress) of -1 . Although the R values for the Lens septum may be more negative than -1 , empirical data does not exist. Extrapolation below $\mathrm{R}=-1$ is beyond the scope of this note. Therefore for this note, the above endurance limits are used when evaluating stress cycles with $R$ values less than $R=-1$. Since texture, microstructure, surface finish, temperature and more play such a detrimental role in fatigue, and because the septum contains welded joints, the average of the notched and unnotched endurance limits will be used for comparisons with developed stresses ( $57.5 \mathrm{ksi}$, 3.96E $8 \mathrm{~Pa}$ ).

Another area of high cyclic stresses in the septum is the septum endcap. To resolve the dominant stress direction for cyclic stress analysis, a local coordinate system is used for Figures 31 through 39 . The coordinate system is cylindrical in nature with the axis of the cylinder lying on the global $z$ axis (hoop direction). Thus it is actually toroidal in shape. In the local coordinate system, the positive $\mathrm{x}$ direction is radially out from the center of the endcap radius; the y direction is tangential, and the $z$ direction is the same as before in the global coordinate system. Thus the dominant stresses appear to be in the local y direction as well as the local/global $z$ direction (Figures 34 through 39). The stress distribution in y are akin to bending stresses in the end caps, whereas the stress distribution is $z$ is that of the hoop stress in the inner conductor tube described earlier. It is not clear how to 
combine these stresses in order to achieve a concise stress cycle for fatigue performance comparison. In lack of a better method, the stresses are vectorally added together and shown in Table 4 . One can see that, although the very low $\mathrm{R}$ values cannot be accounted for, the maximum stresses are well under the endurance limits for the material.

Figures 22 through 24 show some local stress concentrations in the area of the nickel seal between the steel body and the septum. This is most likely due to differing thermal expansions of the body and septum. Since the nickel seal is not actually modeled by the simulation, peak stresses are probably less than indicated since some of the stress will be relieved by relative motion of the nickel seal. However, the effect of this movement on the effectiveness of the seal is unknown.

Figures 40 through 42 show the pressure distribution on the Be end window from the lithium volume before, during, and after a pulse. Although these structural results do not indicate any problems with high stress loading, the pressure distributions could be used for future detailed analyses with the goal of optimizing window geometry.

\section{CONCLUSION}

\section{A. Summary}

The structural results of this analysis do not indicate failure of any of the lens components by high stress. Uncertainties with comparing fatigue limits with $R$ values less than negative 1 cast some doubt on the safety factor of the septum inner conductor tube. With the added negative performance factors of welded joints, surface finish, microstructure, texture orientation, etc., safety factors of at least 2 are recommended (under the unnotched endurance limit). Although cyclic compressive stresses in the septum endcaps are greater, the expected area of failure is in the inner conductor tube itself (greatest maximum stress).

The most troubling result is the discovery that lithium/titanium separation may be occurring at peak current. This event could be detrimental because the void(s) created will probably not be uniform and will interfere with the smooth passage of current. One could imagine local spots of extreme heating or even electrical arcs occurring across these voids. Thermal effects such as these could affect the fatigue performance of the neighboring septum inner conductor tube material or even cause catastrophic failure if the localized heating was severe enough to weaken the tube wall. 
Past failures of lenses indicates that pulsing at high gradient even for a short time on the test stand may shorten the lens lifetime at lower gradients. If lithium/titanium separation is occurring at the higher gradients, it could be that damage created by the separation pre-disposes the lens for early demise. It is also interesting to note that Lens \#26 which failed on the test stand at low gradient had a very low pre-load (less than 500 psi). This also indicates that lithium/titanium separation may be a significant issue.

To investigate further, a smaller model of just a slice of the lithium central conductor cylinder was created. The results indicated that the separation effect was not evident at $500 \mathrm{kA}$ of current and began appearing near $590 \mathrm{kA}$. This indicates that the lithium pre-load of 2,000 psi is not enough to suppress lithium/titanium separation at full design gradient $(670 \mathrm{kA})$. This smaller model however assumed plane strain boundary conditions at the ends of the lithium slice. This ignores the large amount of displacement of the lithium and thus underestimates the amount of pre-load needed. More investigations into this effect with the full model are warranted. To fully combat the separation effect, a high enough pre-load should be used to keep the hoop stress in the septum inner conductor tube positive throughout the pulse.

\section{B. Future Work}

The results presented here are a major step toward understanding the structural behavior of the Collection Lens. However more work is required to build a full picture of how and why the present lens design fails. Obviously more investigation into the lithium/titanium separation issue is of high priority. Since the lithium pre-load is less when a lens is cold (first pulse), this condition must be analyzed for a worst case scenario. It may be possible to allow separation to occur for a finite number of cold pulses without significantly shortening the lifetime.

The material properties used in this ANSYS model should also be investigated. Of high interest are the structural properties of lithium. Although the modulus and yield strength of the lithium were measured for this analysis, poisson's ratio and tensile strength would also be desirable. In addition the time dependence of these properties should also be investigated to ensure that the modulus of lithium remains low even at high rates of load application (as assumed in this model). Temperature dependence of material properties should also be investigated. Although it may be too lengthy an undertaking to iterate to a proper solution, it should be possible to bound the problem by looking at each property individually and gauging the end effect on the model. Or for a 
conservative estimate, simply use worst case values utilizing the current analysis for a first guess at average temperature.

These results should also be compared with the upcoming Lens autopsy results. Although it may be difficult to discern

lithium/titanium separation from a dissected and failed septum, it is worth the effort to rule out other sources of failure.

Finally, although the Be end window design looks adequate from this analysis, it should be checked with a smaller more localized analysis using the pressure distributions presented here. It may be possible to further optimize the window design to decrease thickness without jeopardizing structural integrity. 


\section{Appendix A: \\ Figures and Graphs}




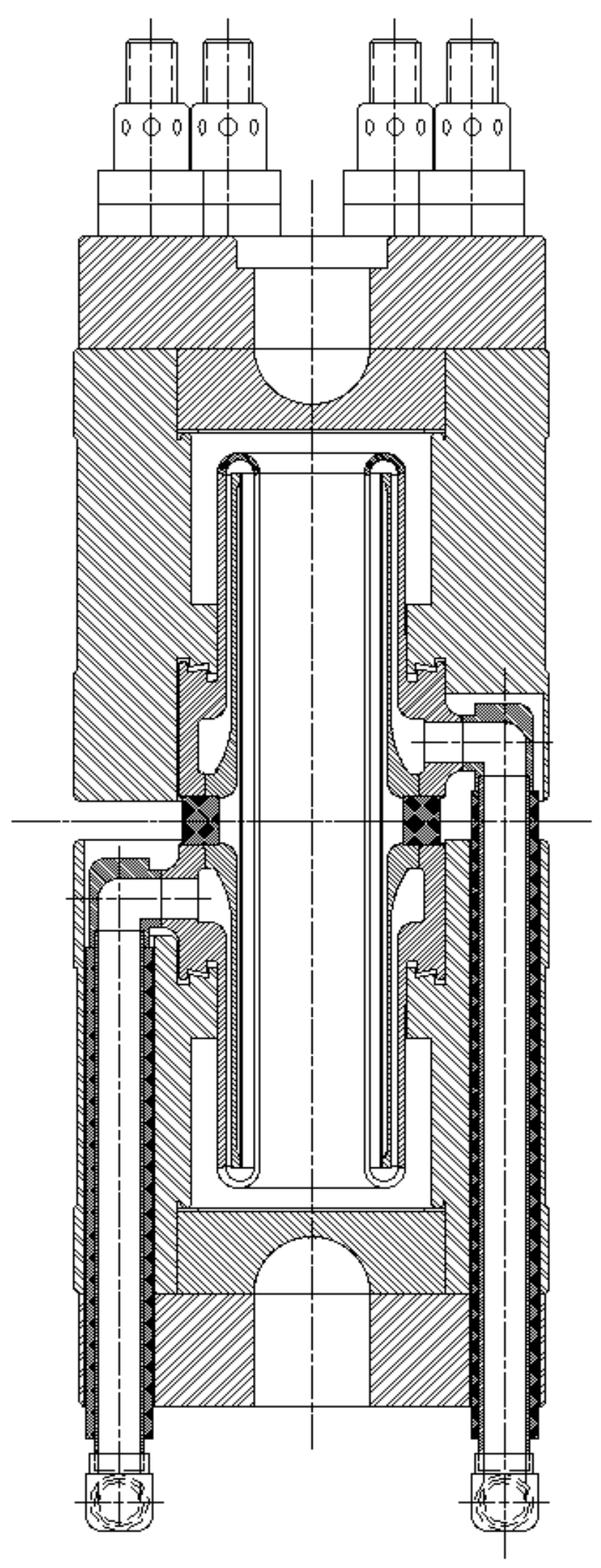

Figure 1. Cross-section view of Collection Lens current design. 


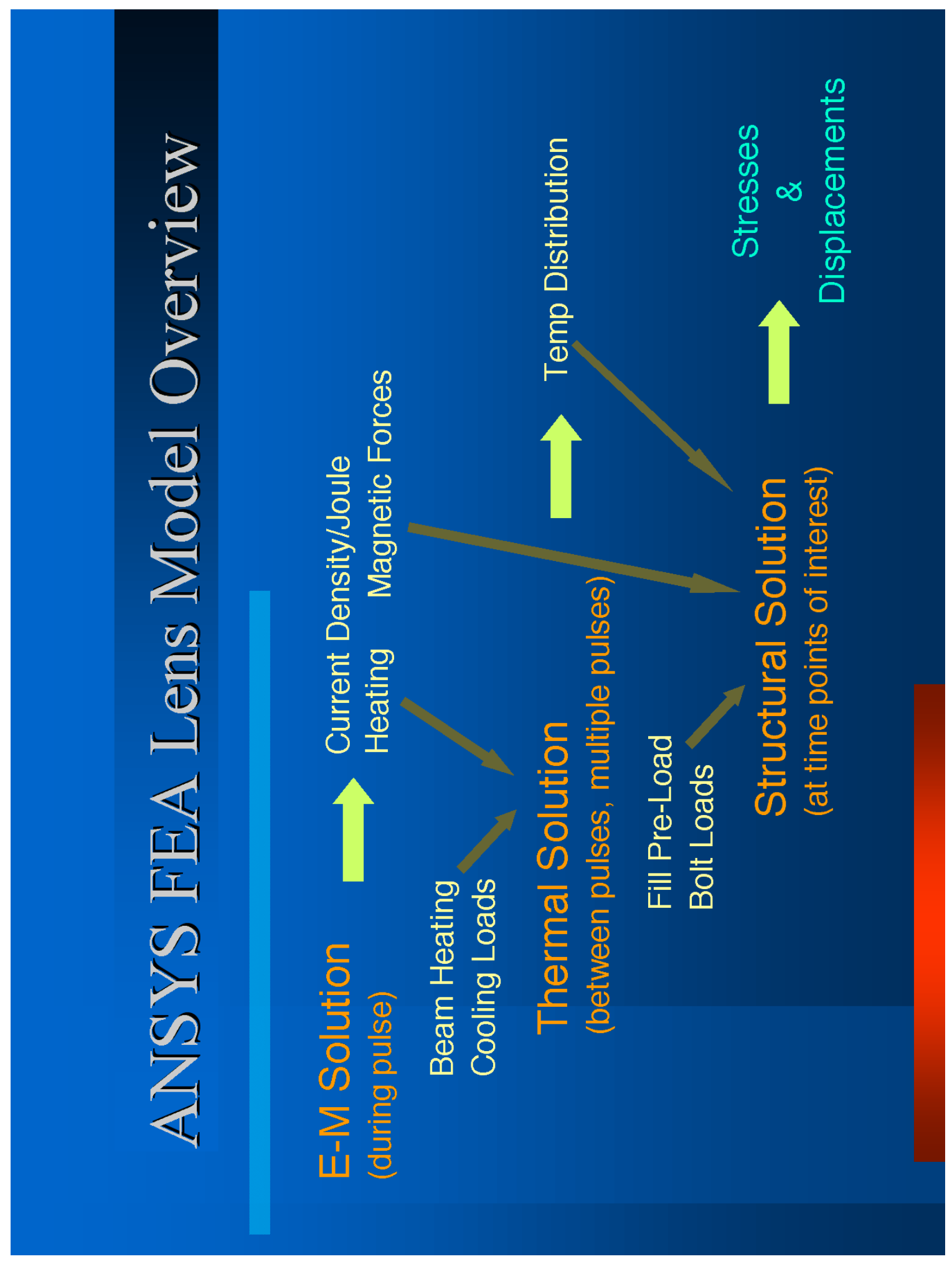

Figure 2. Diagram of ANSYS model overview. 
$\xi$

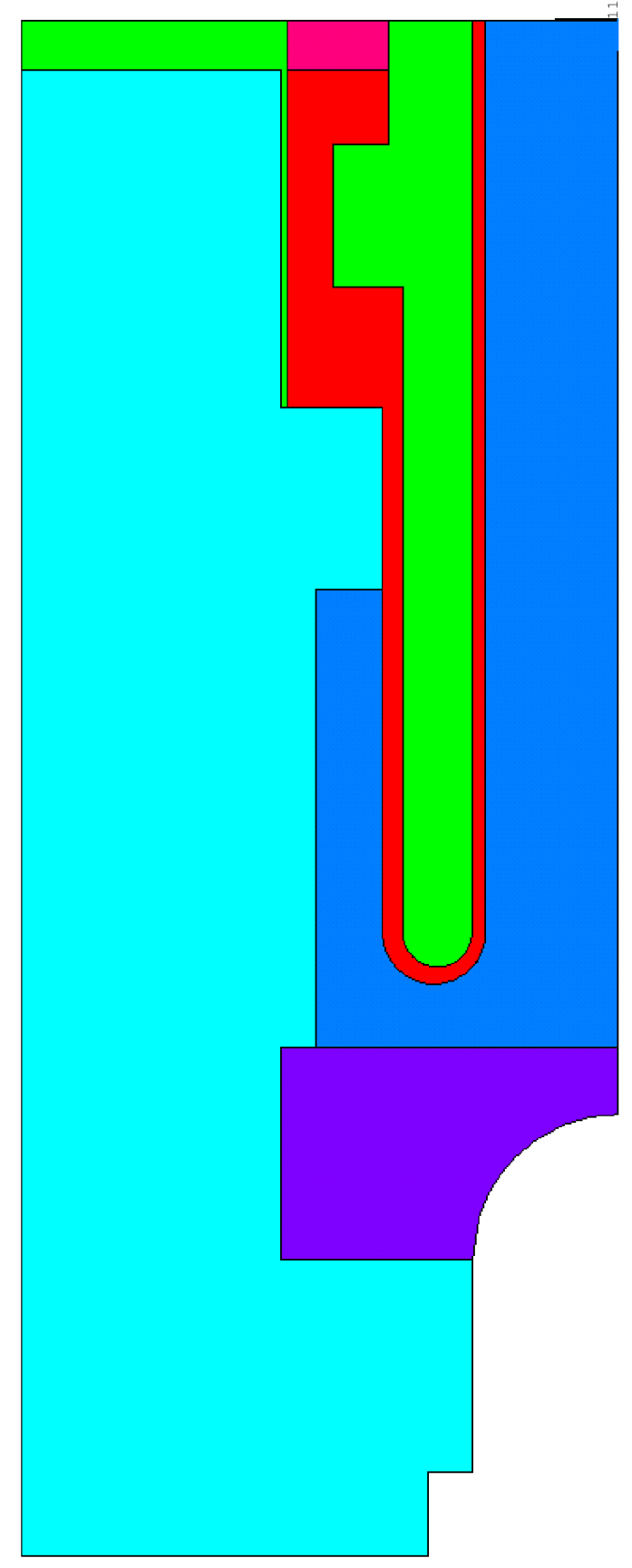

-1
0
0
0
0
0
0
0
0
-1
4
-4
-1
0
-7
-7
0

Figure 3. ANSYS Model Geometry. 

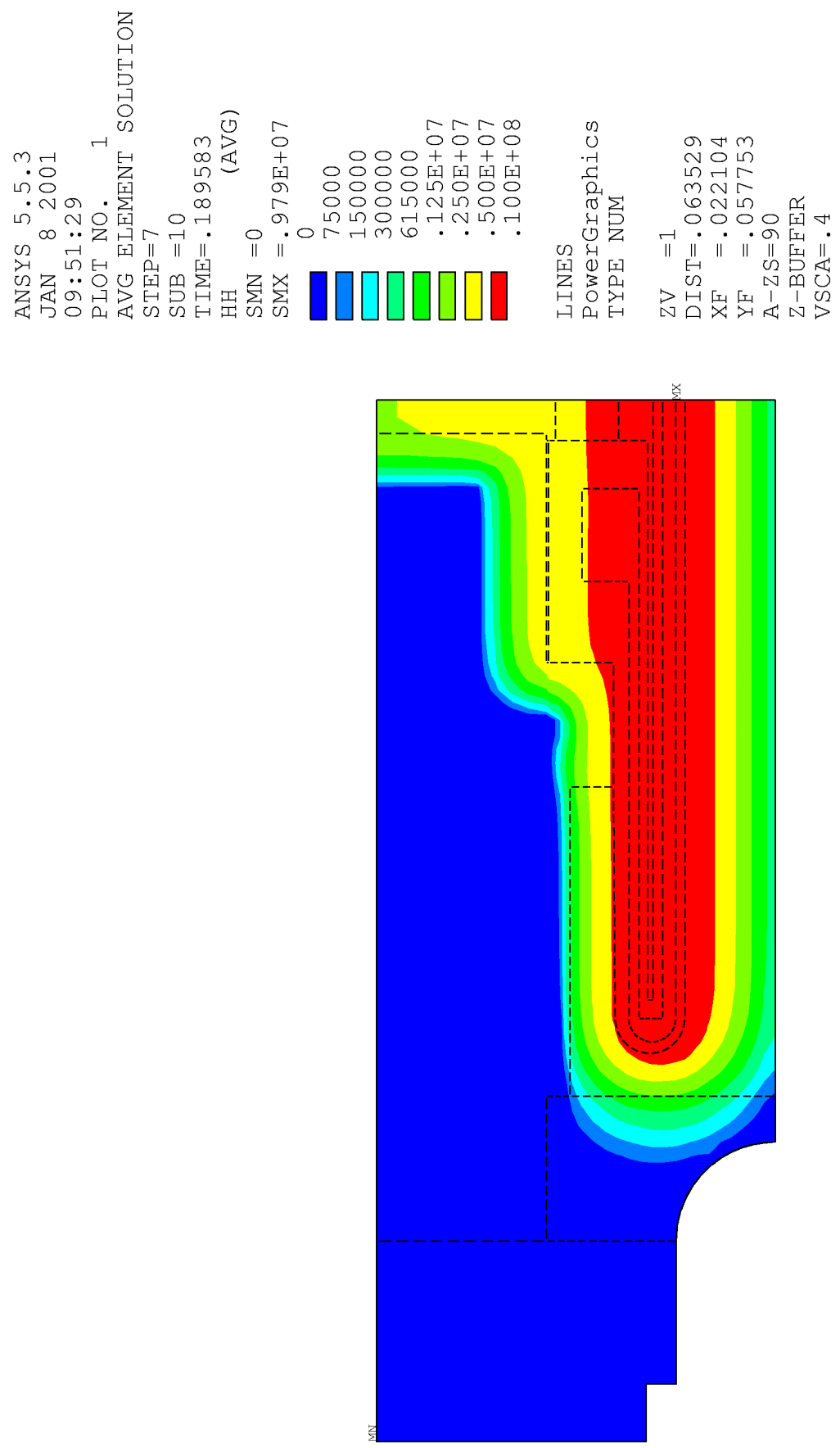

Figure 4. Magnetic Field Results. 

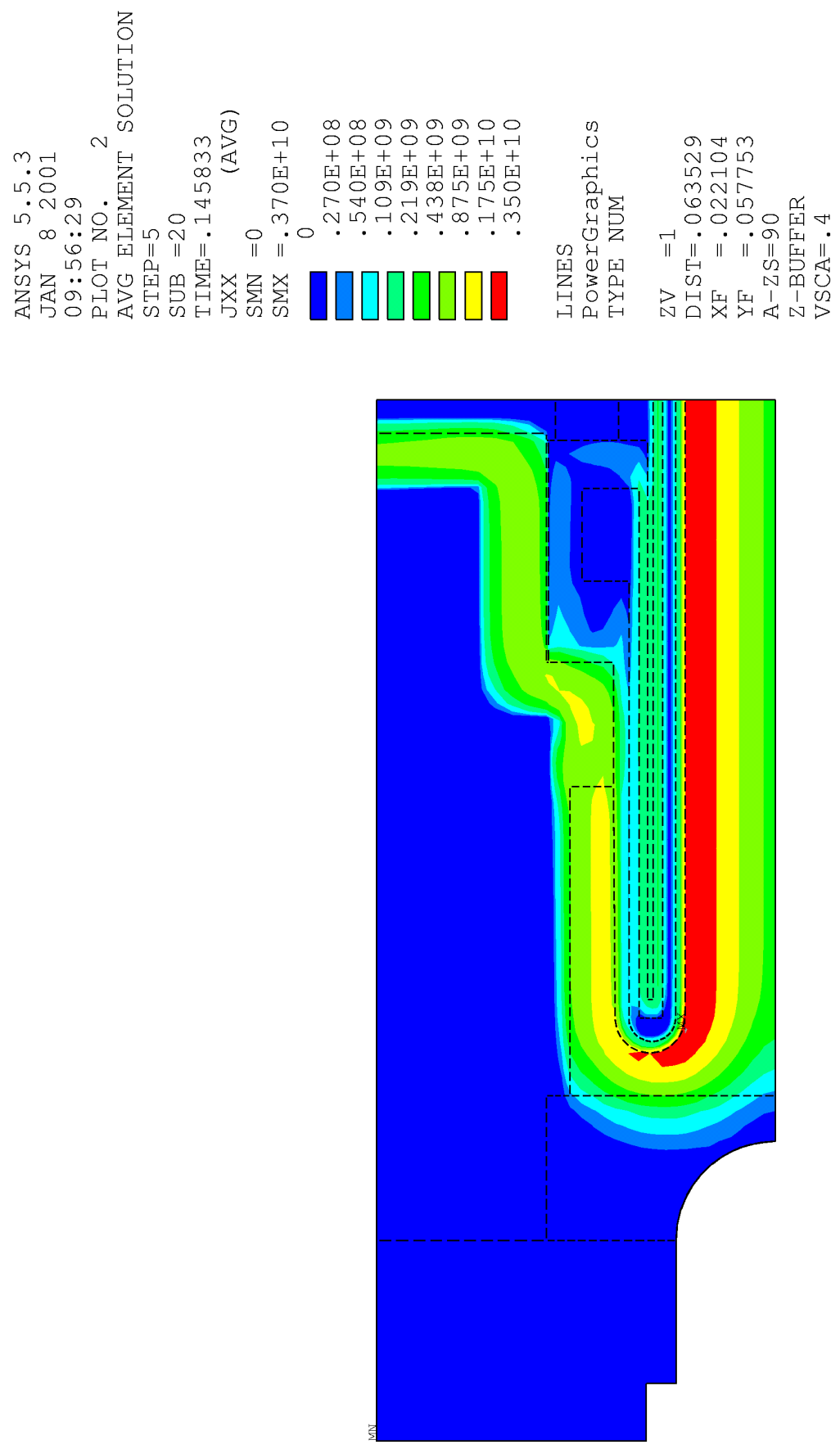

Figure 5. Current Density Results. 

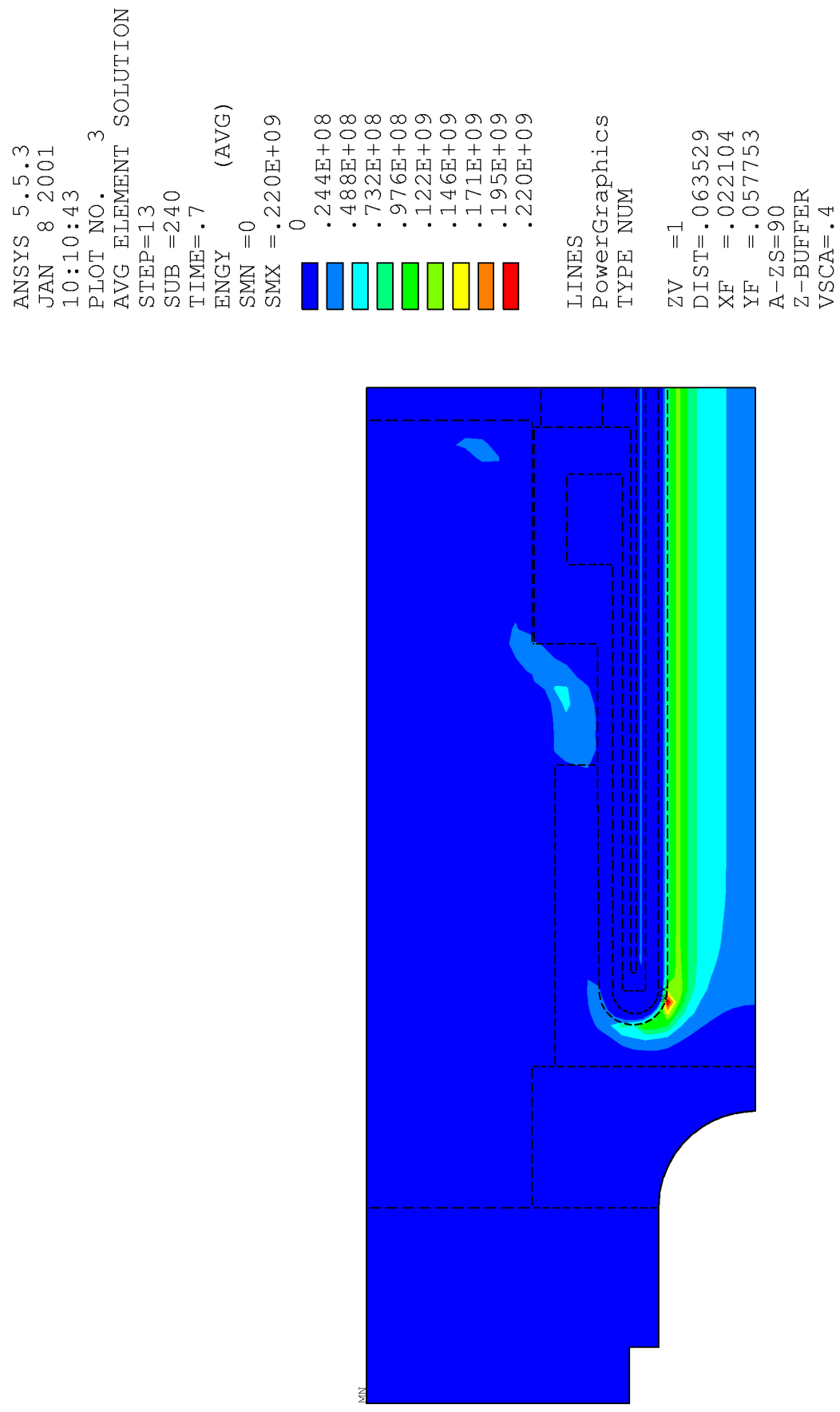

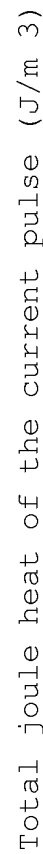

Figure 6. Joule heat deposition from one pulse. 

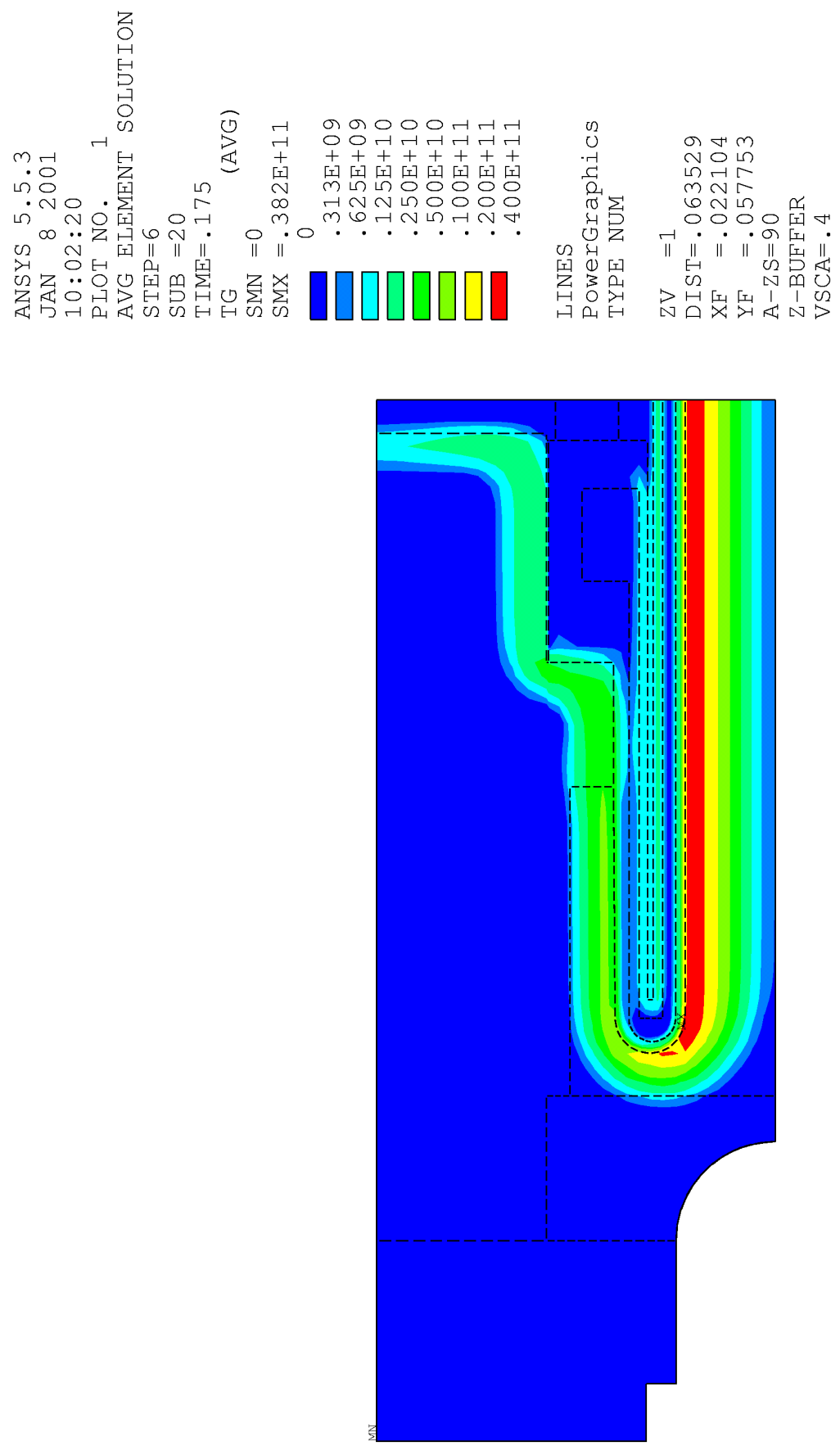

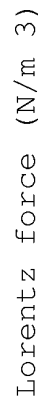

Figure 7. Peak magnetic force distribution during pulse. 


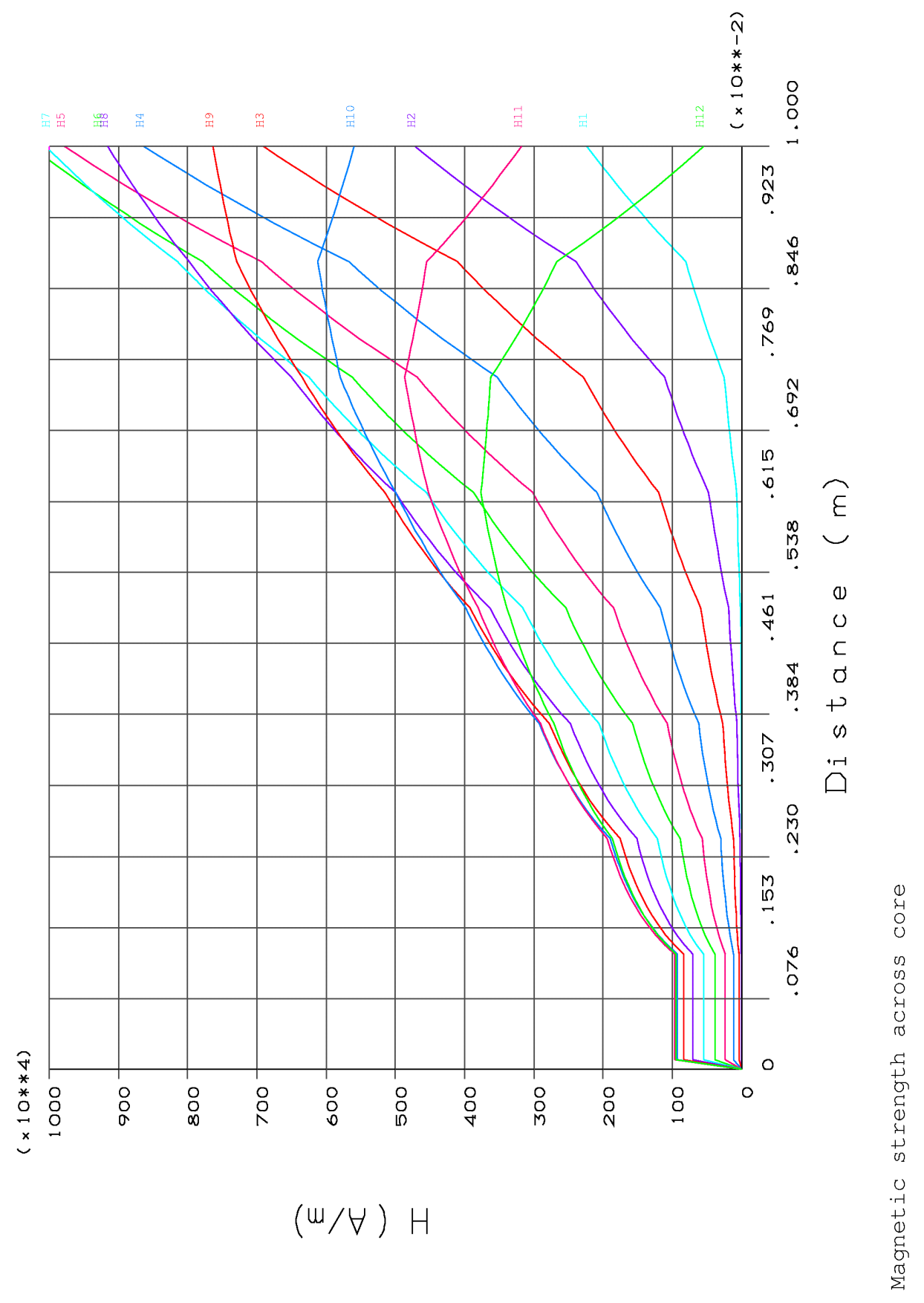

Figure 8. Magnetic field strength vs. radial distance in Li core. 
そ

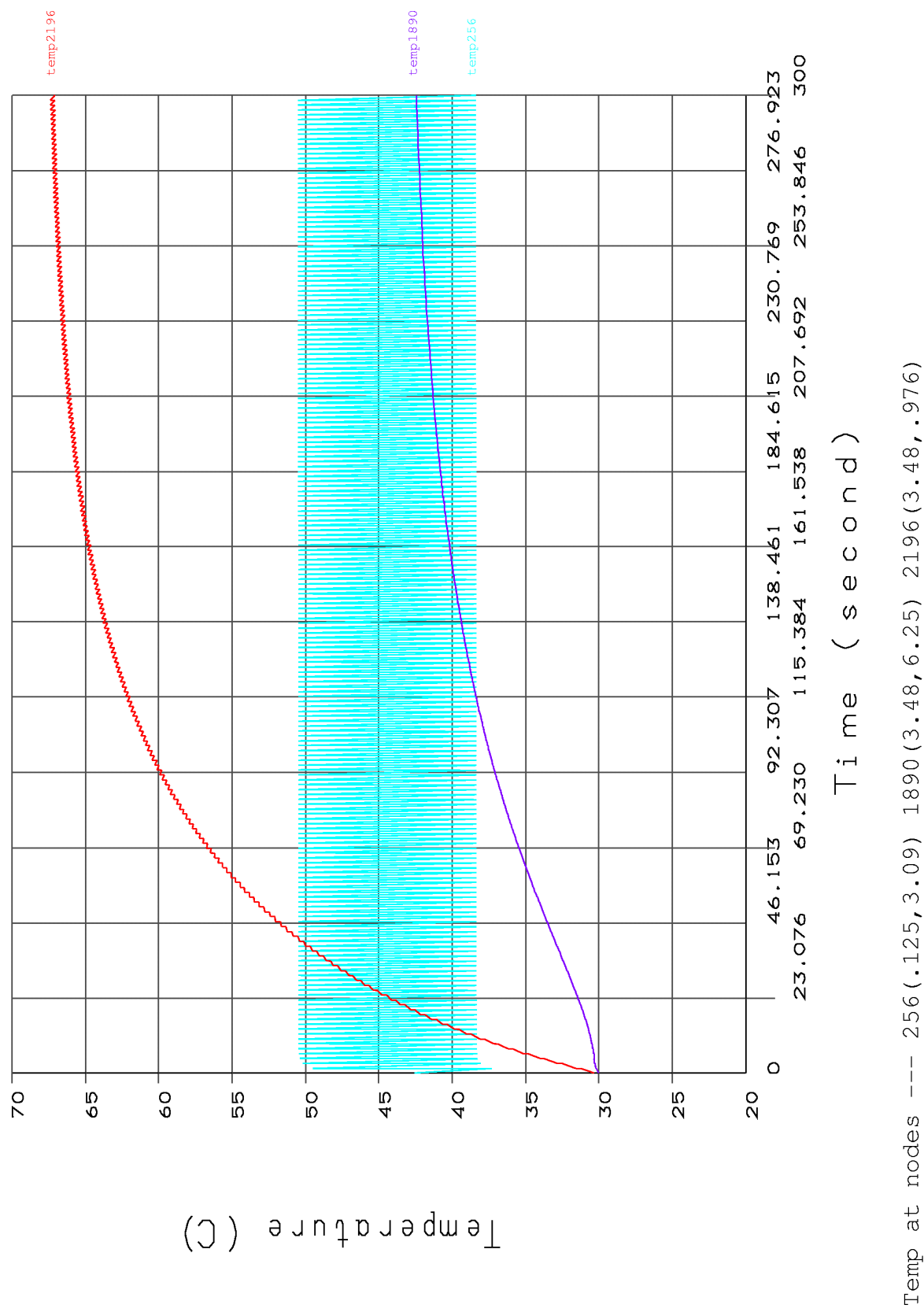

Figure 9. Temperature rise at three locations $(\mathrm{cm})$ during initial 300 seconds of pulsing (1.5 sec rep rate). 

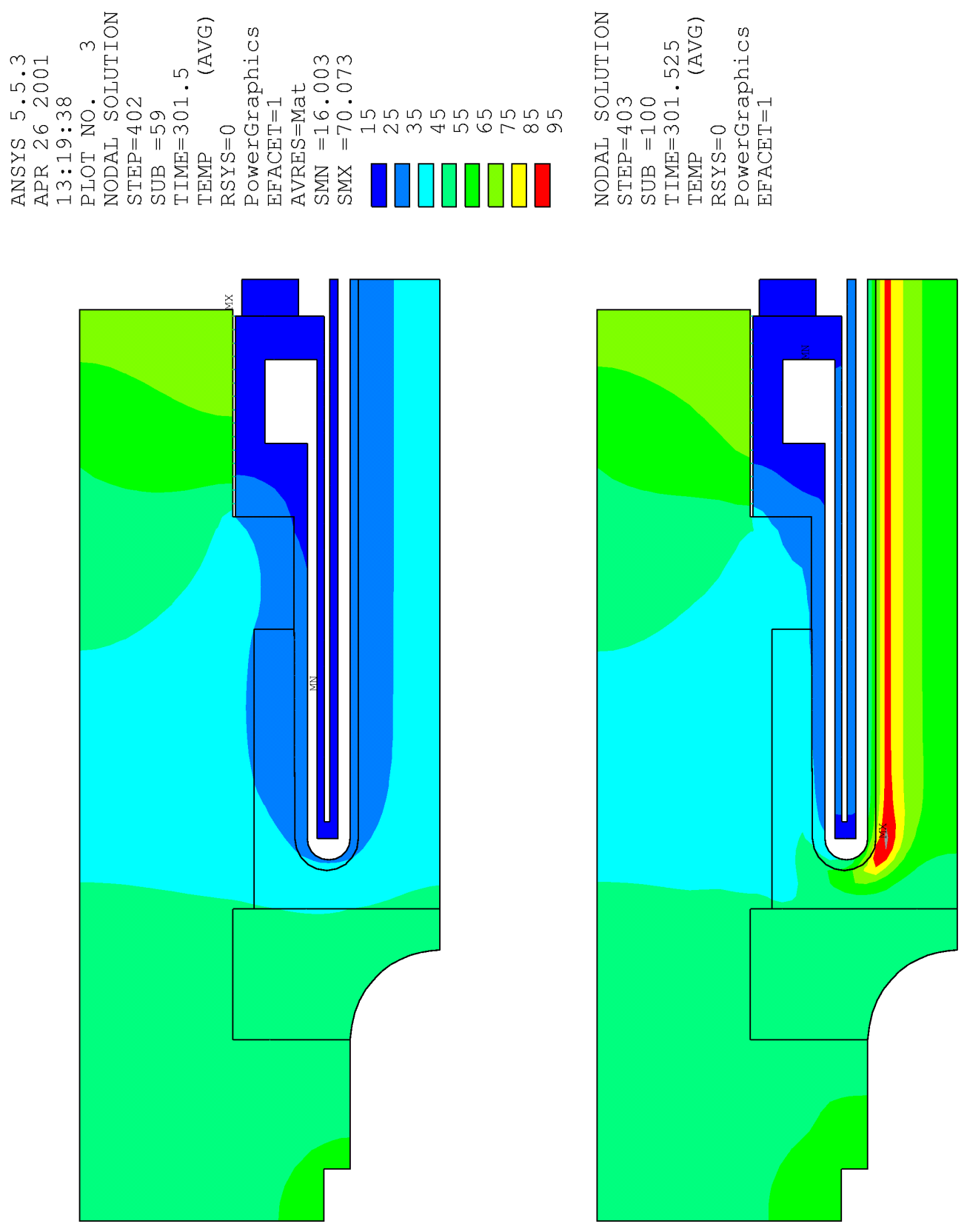

5
0
0
-7
4
7
0
-7
4
4
0
$0-1$
0
0
4
5
5
0
0
4
0
0
50
0
4

Figure 10. Temperature distribution just before (top) and just after (bottom) of a pulse after quasi-static conditions established (degrees Celsius). 
$\xi$

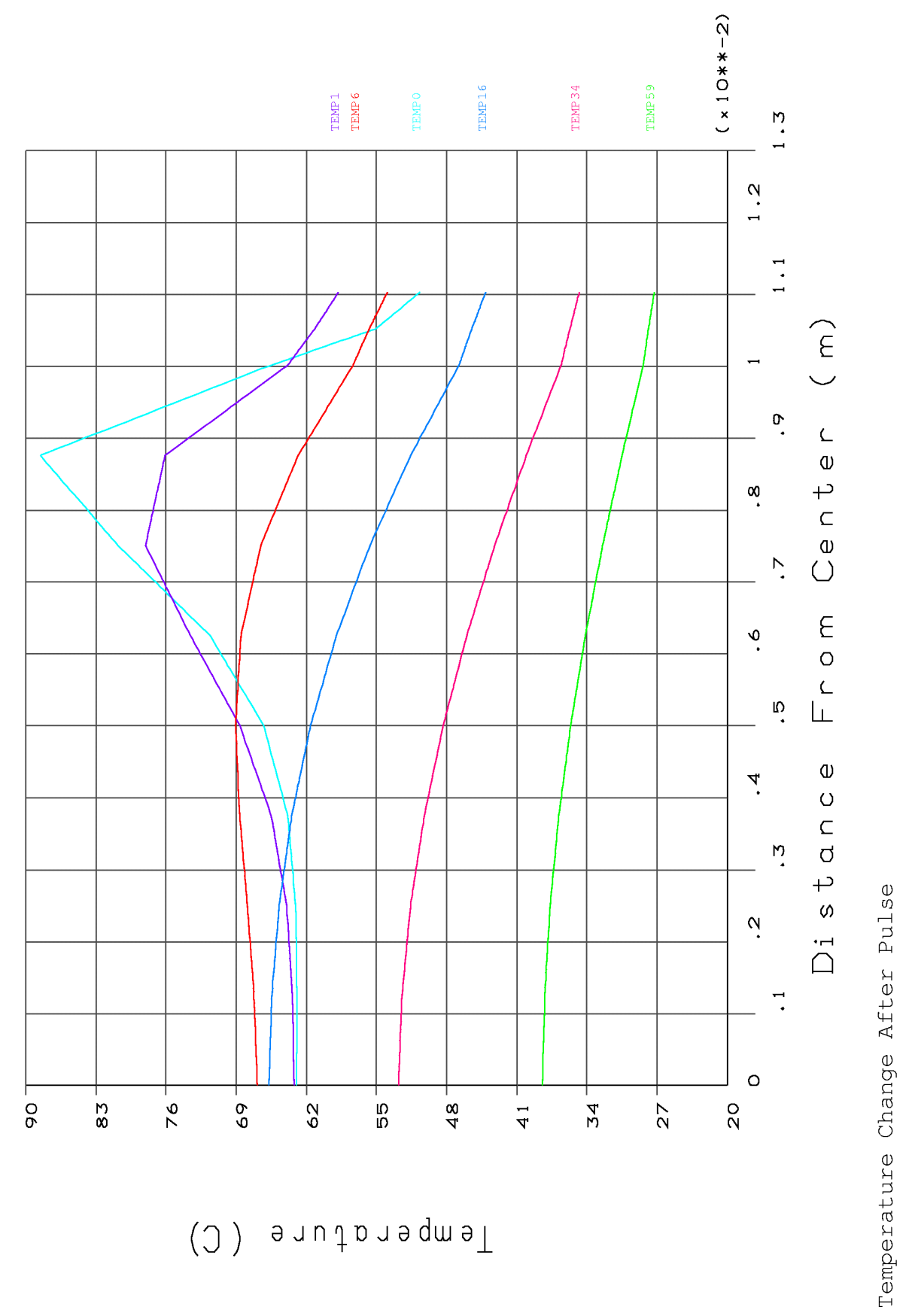

Figure 11. Temperature vs. radial distance in Li core at various time steps. 

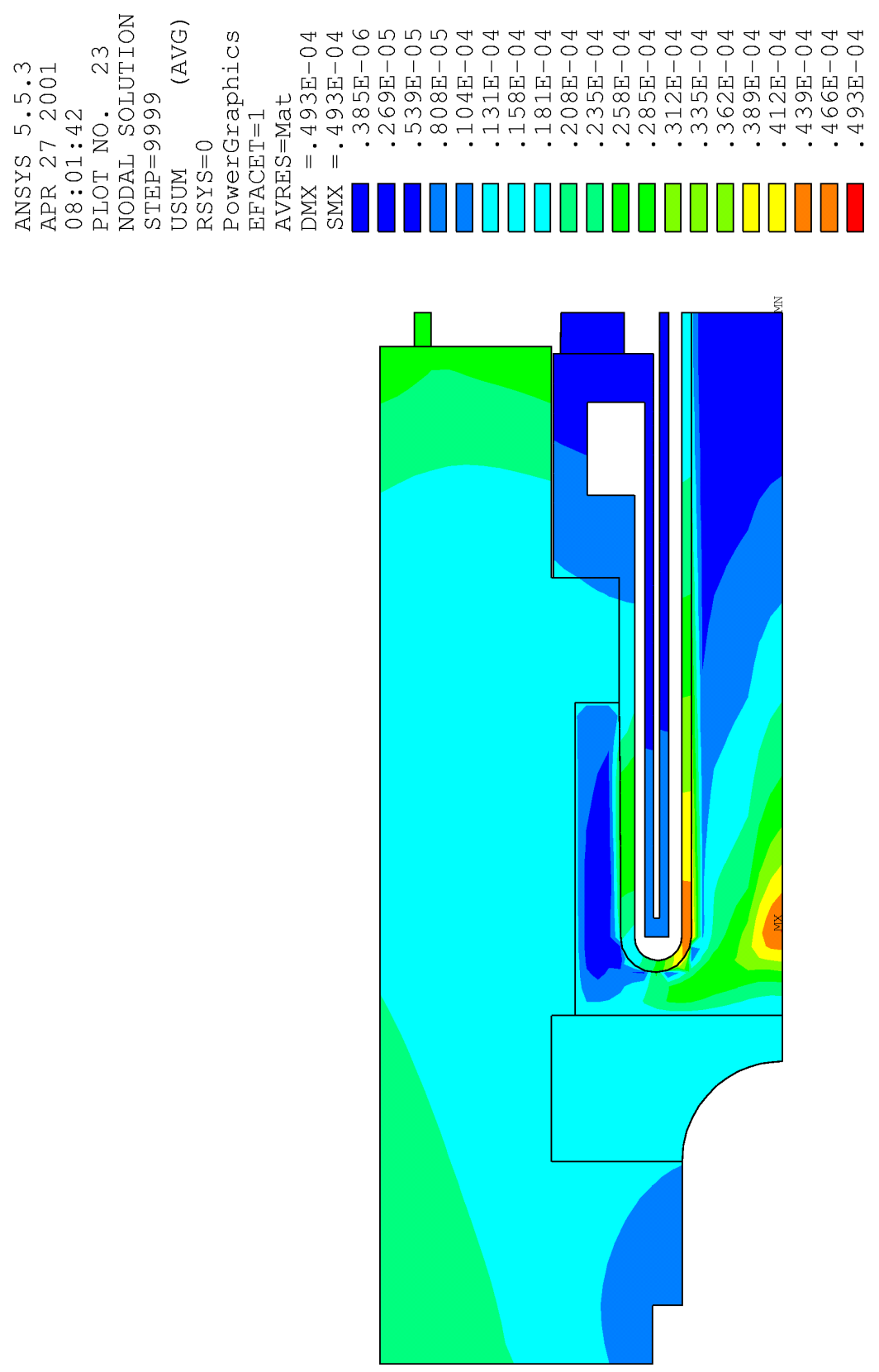

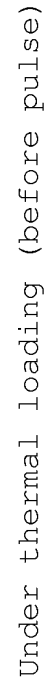

Figure 12. Displacement Sum just before pulse (m). 

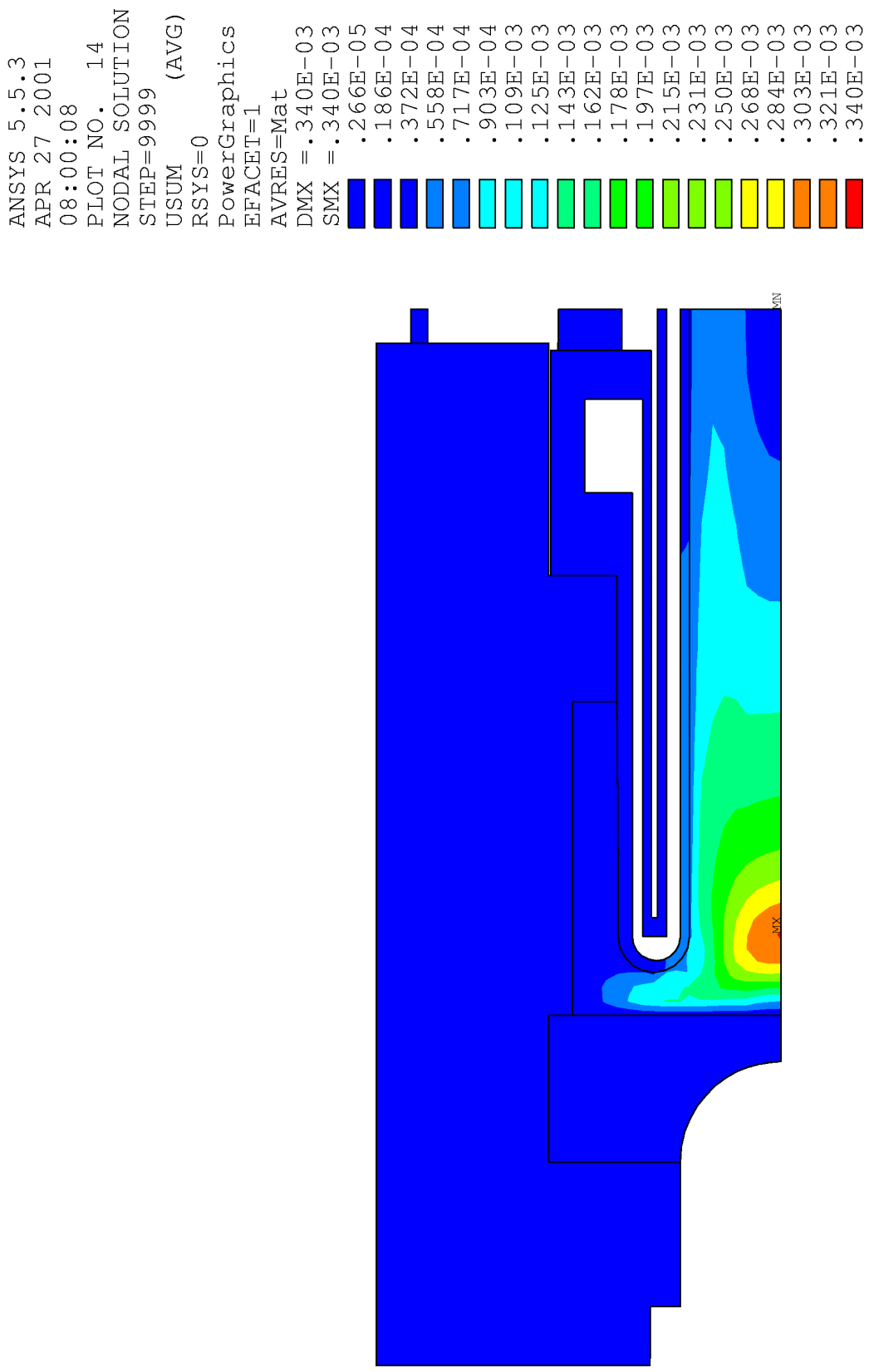

Figure 13. Displacement sum during pulse (m). 

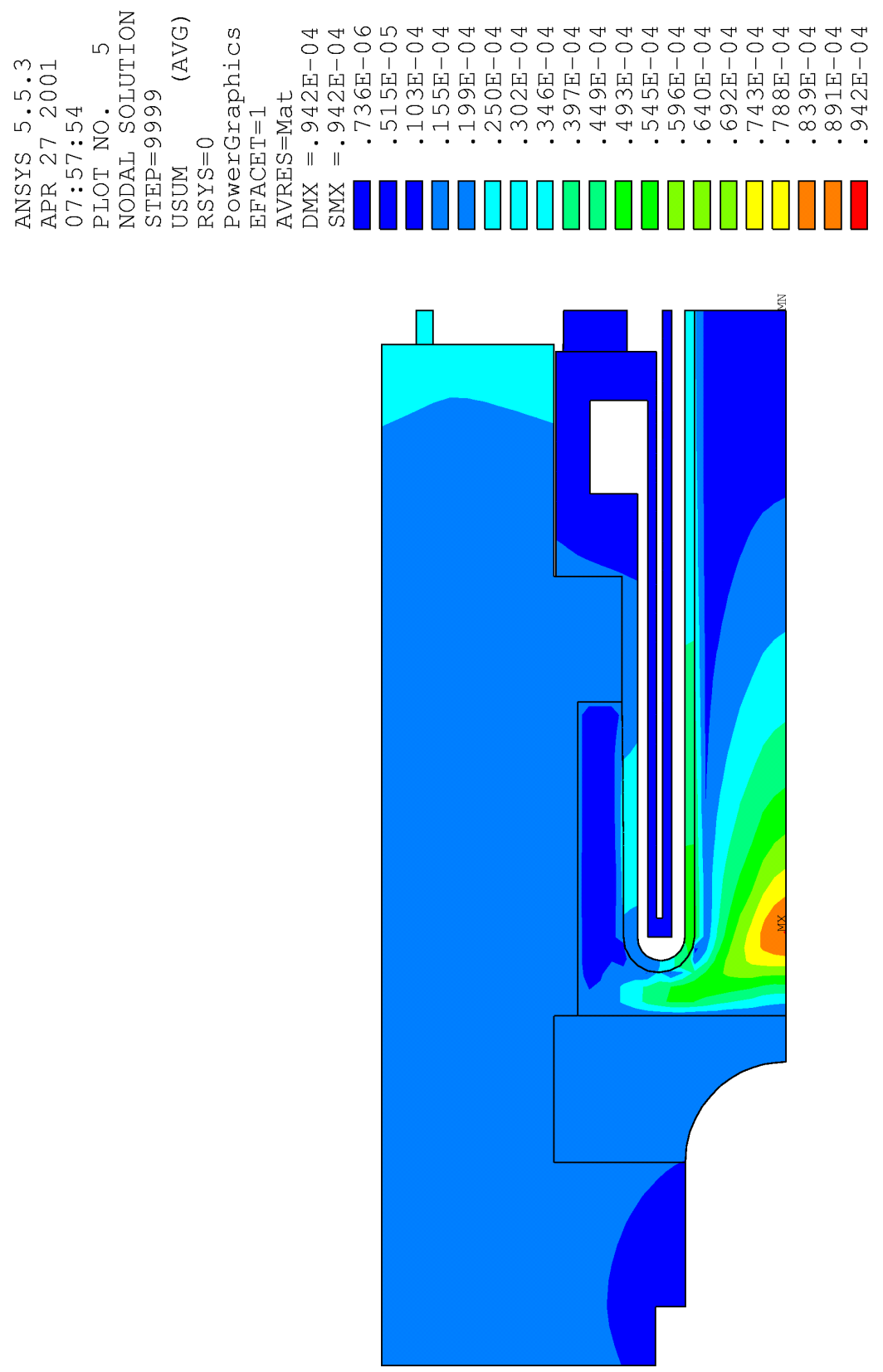

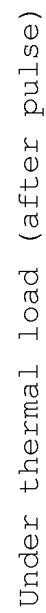

Figure 14. Displacement Sum just after pulse (m). 

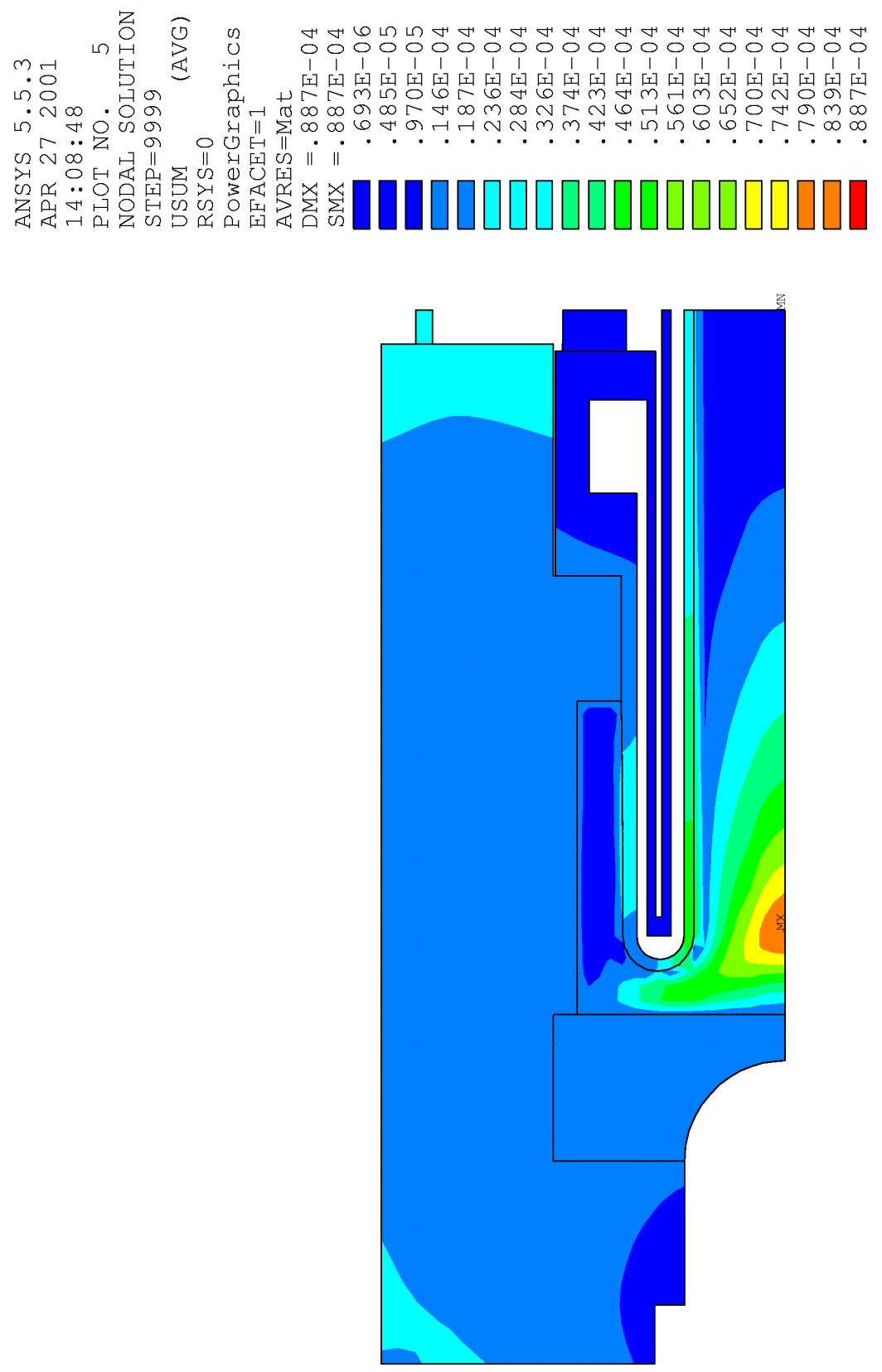

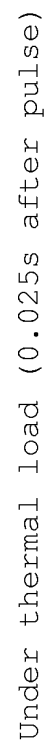

Figure 15. Displacement Sum .025 seconds after pulse (m). 

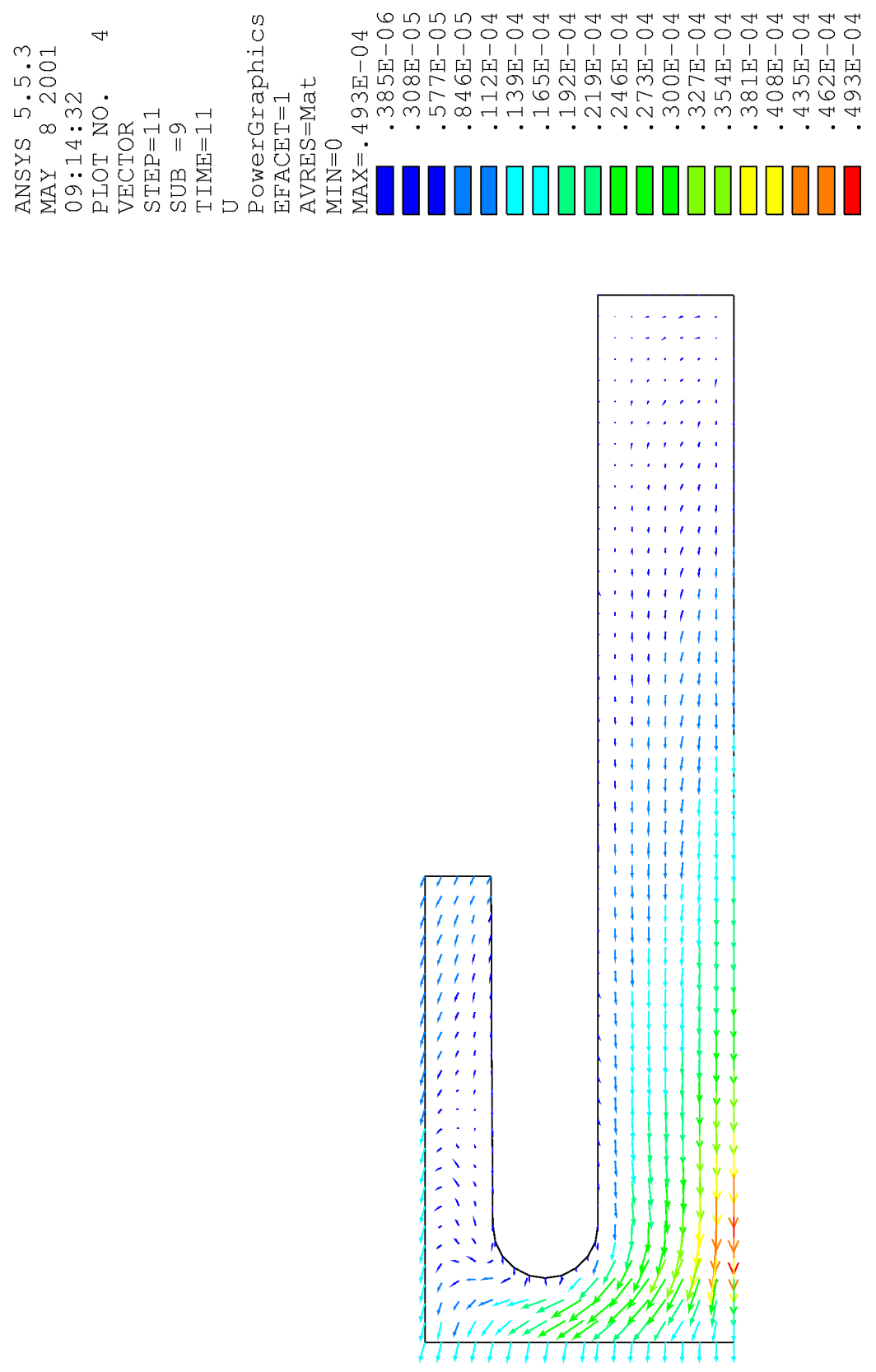

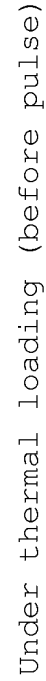

Figure 16. Displacement of lithium just before pulse (m). 

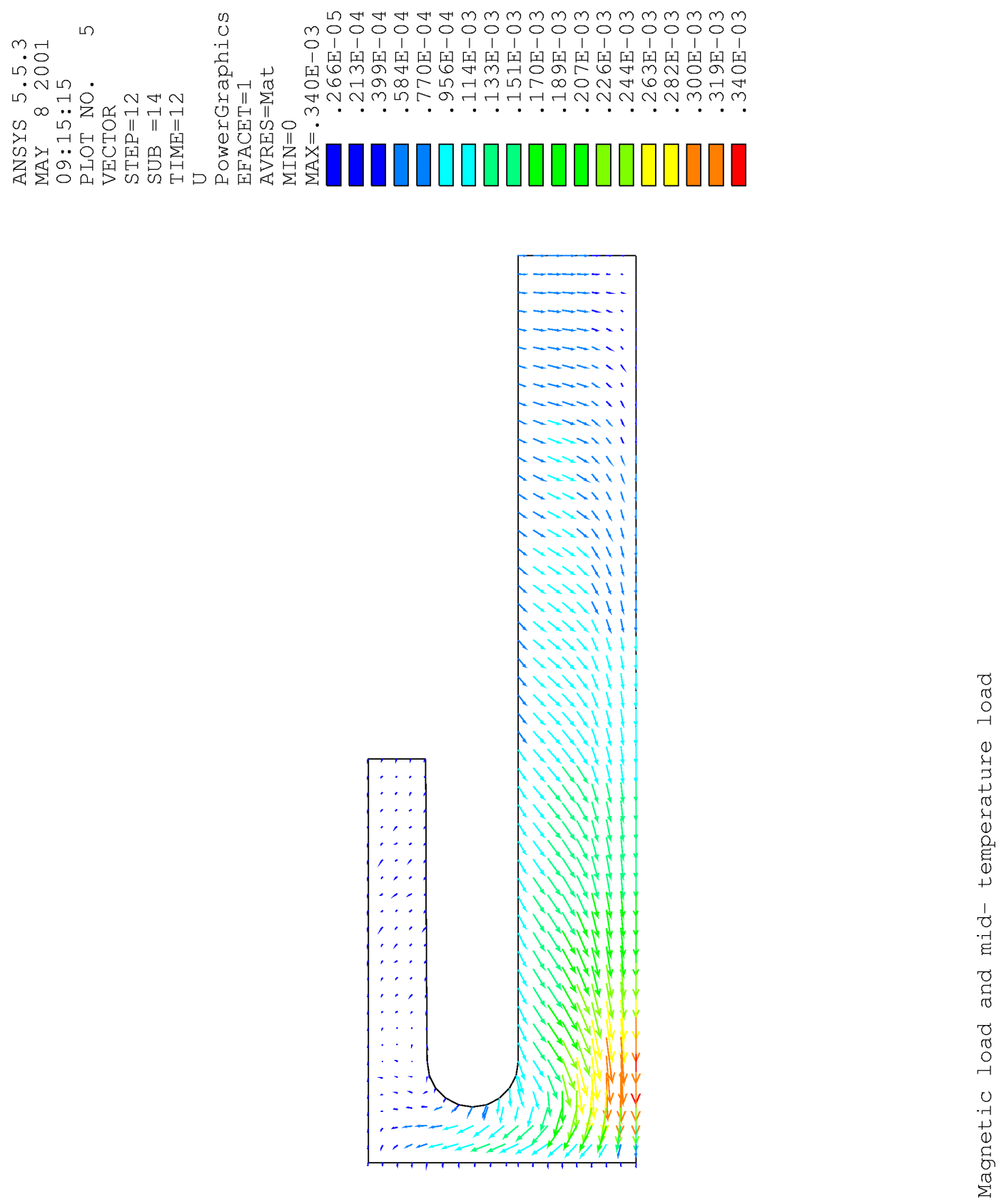

Figure 17. Displacement of lithium during pulse (m). 

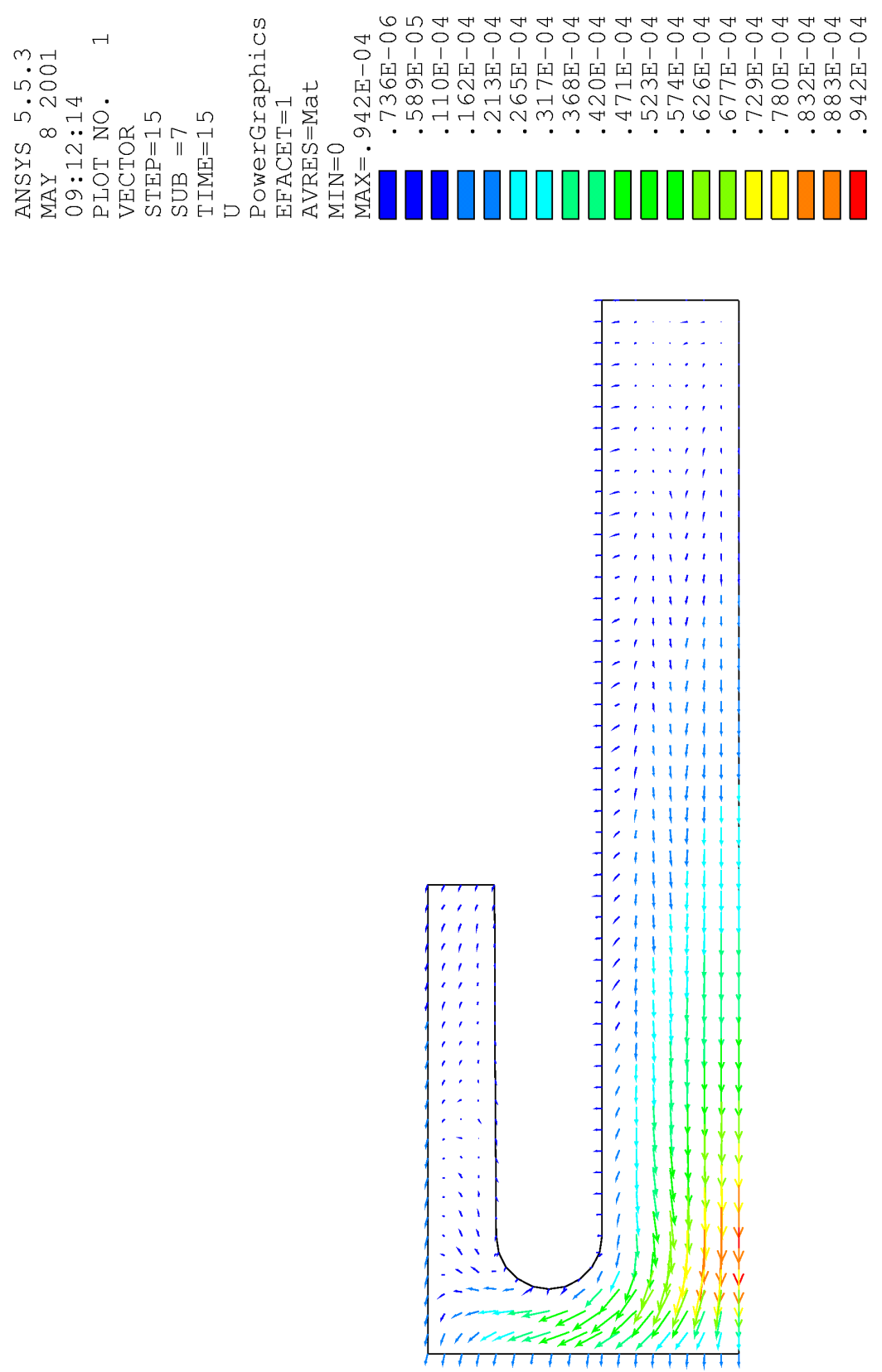

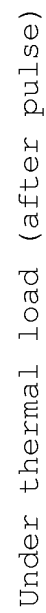

Figure 18. Displacement of lithium just after pulse (m). 

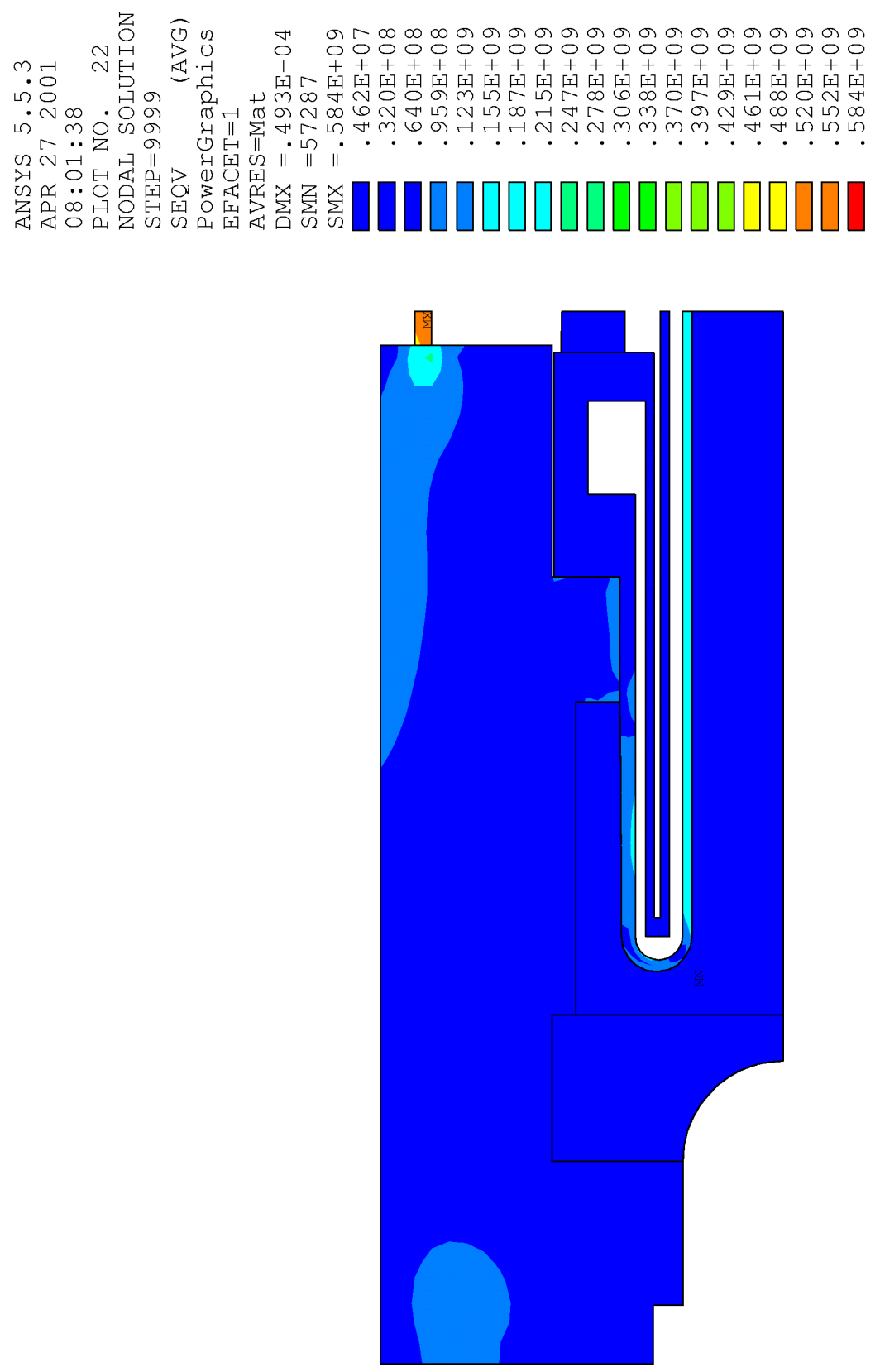

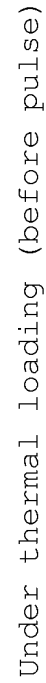

Figure 19. Equivalent Stress just before pulse (Pa). 

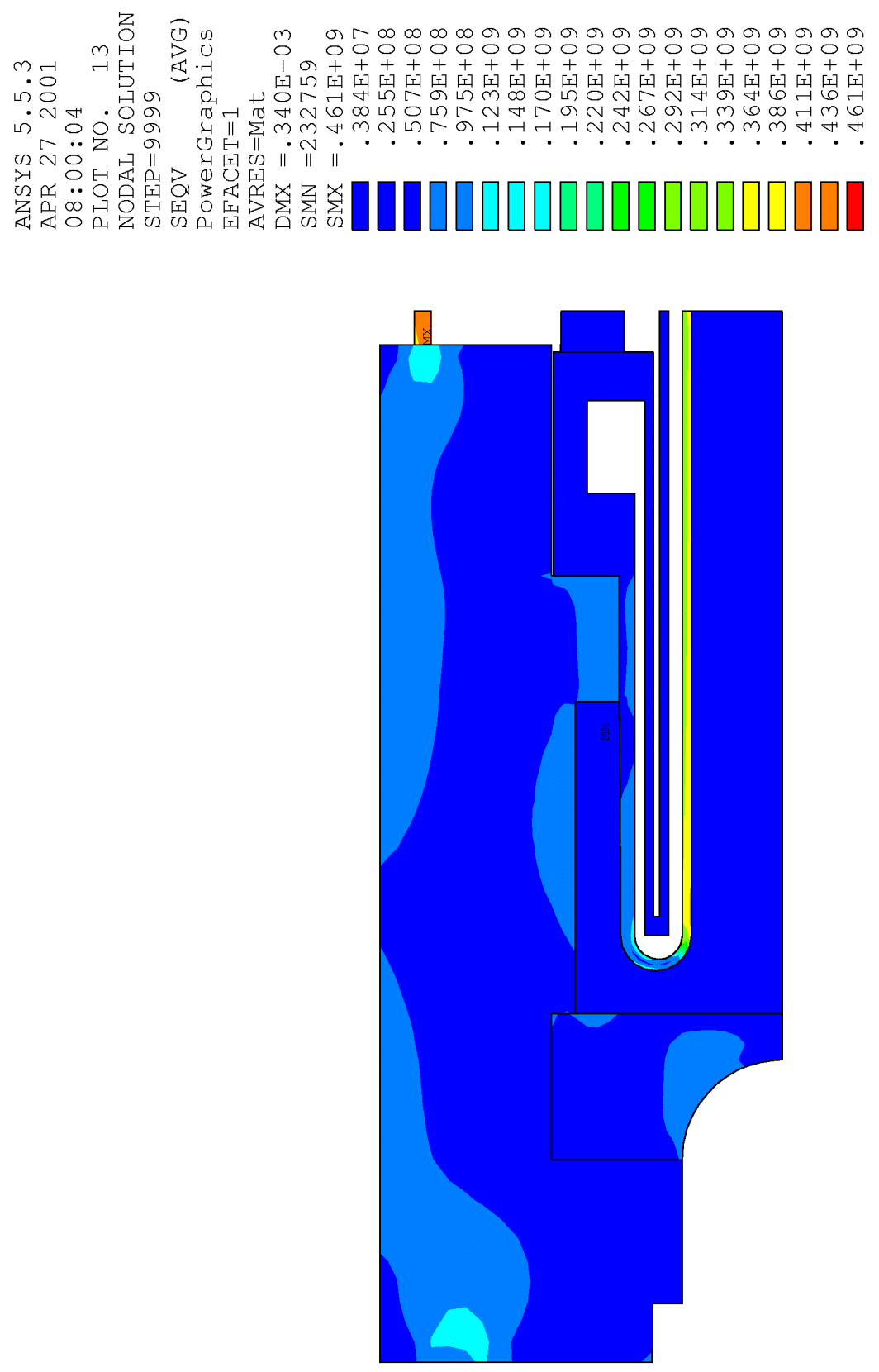

Figure 20. Equivalent Stress during pulse (Pa). 

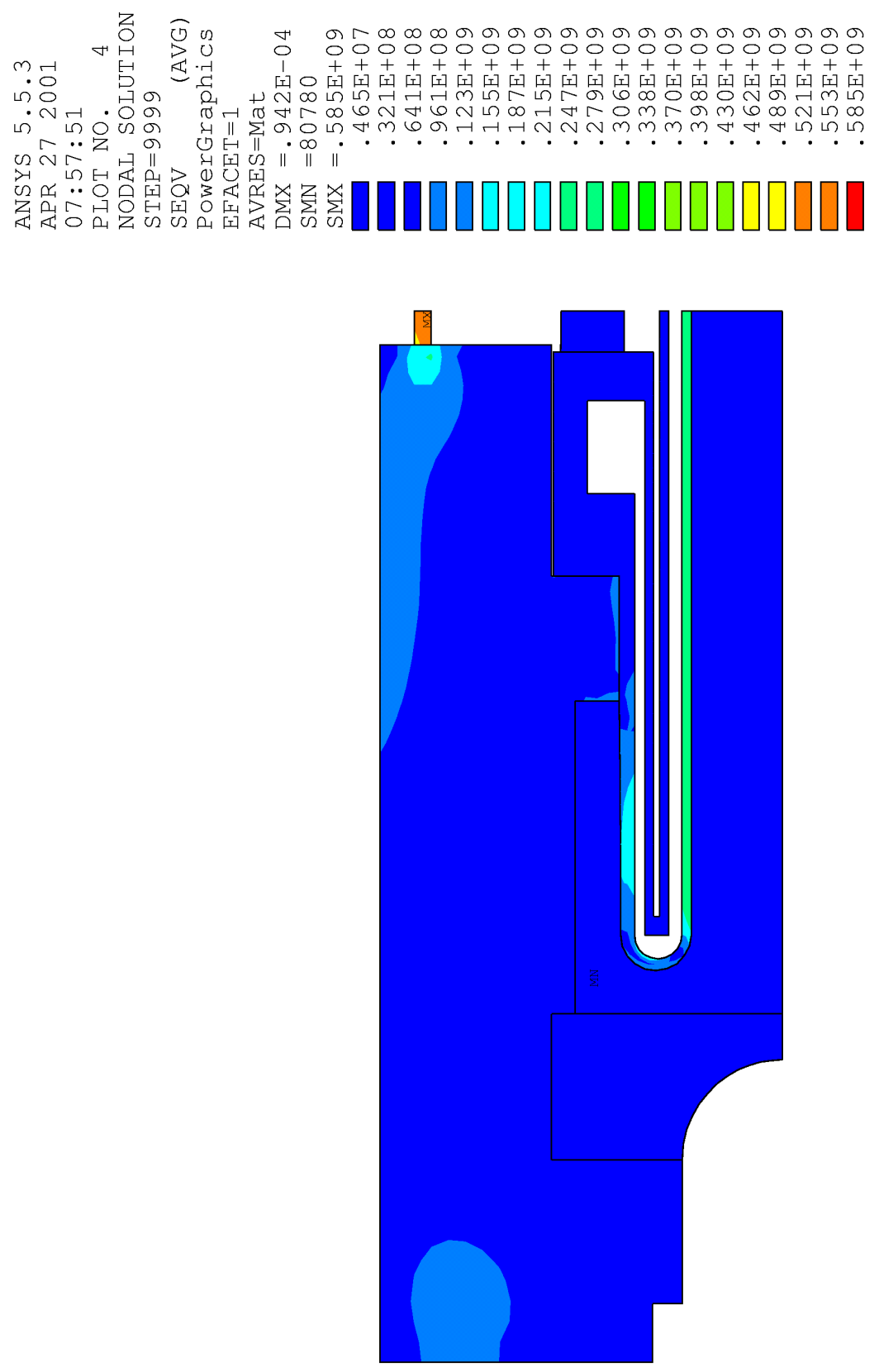

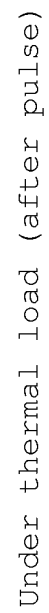

Figure 21. Equivalent Stress just after pulse (Pa). 

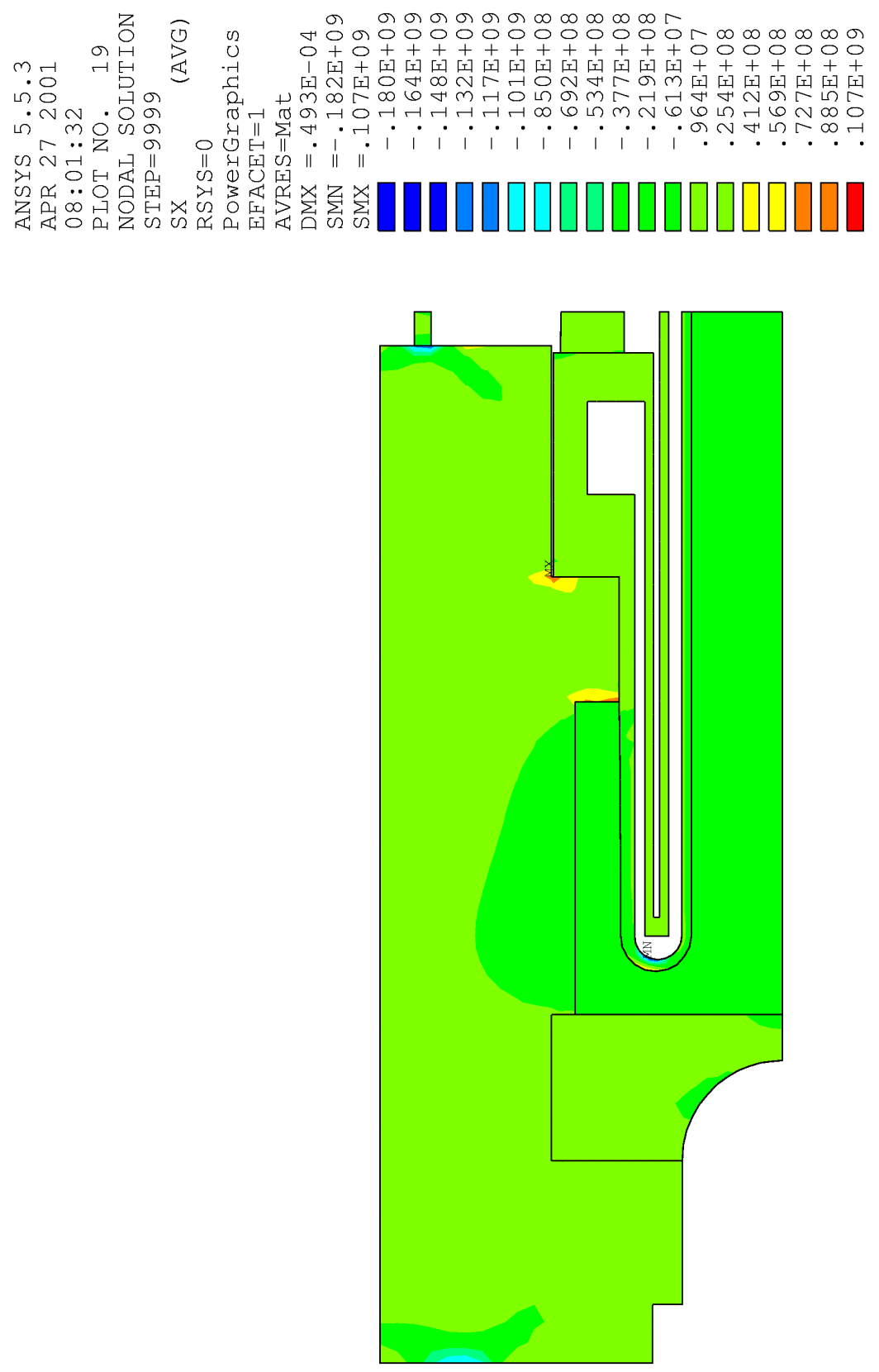

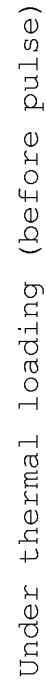

Figure 22. Stress in $\mathrm{X}$ direction (radial) just before pulse (Pa). 

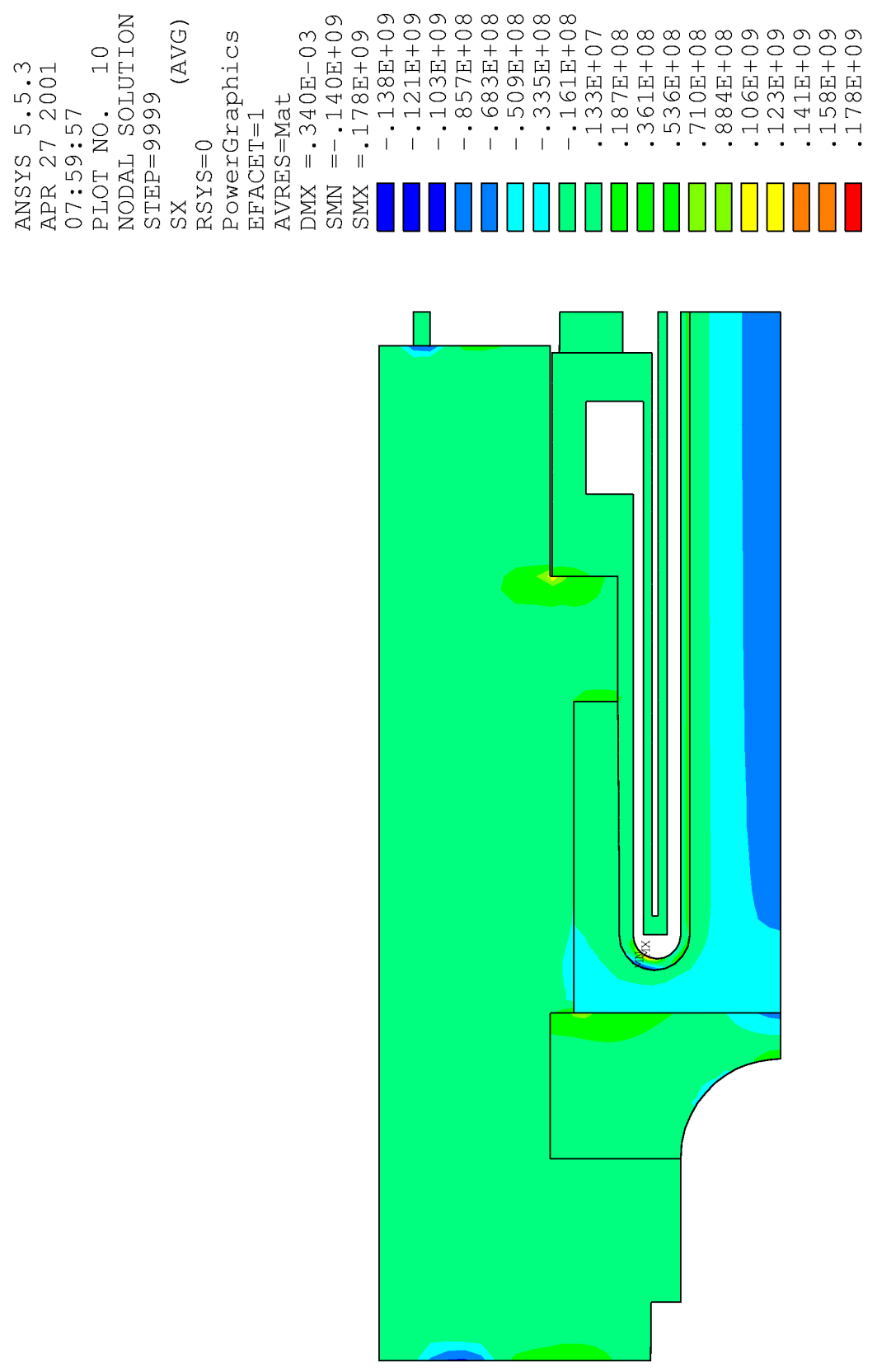

0
0
0
0
0
0
0
0
4
3
0
0
0
4
0
0
0
0
0
1
0
0
0
0
0
0
0
0
0
0
0
0
0
0
0
-7
0
0
0
0
0
0
$\Sigma$

Figure 23. Stress in $\mathrm{X}$ direction (radial) during pulse (Pa). 

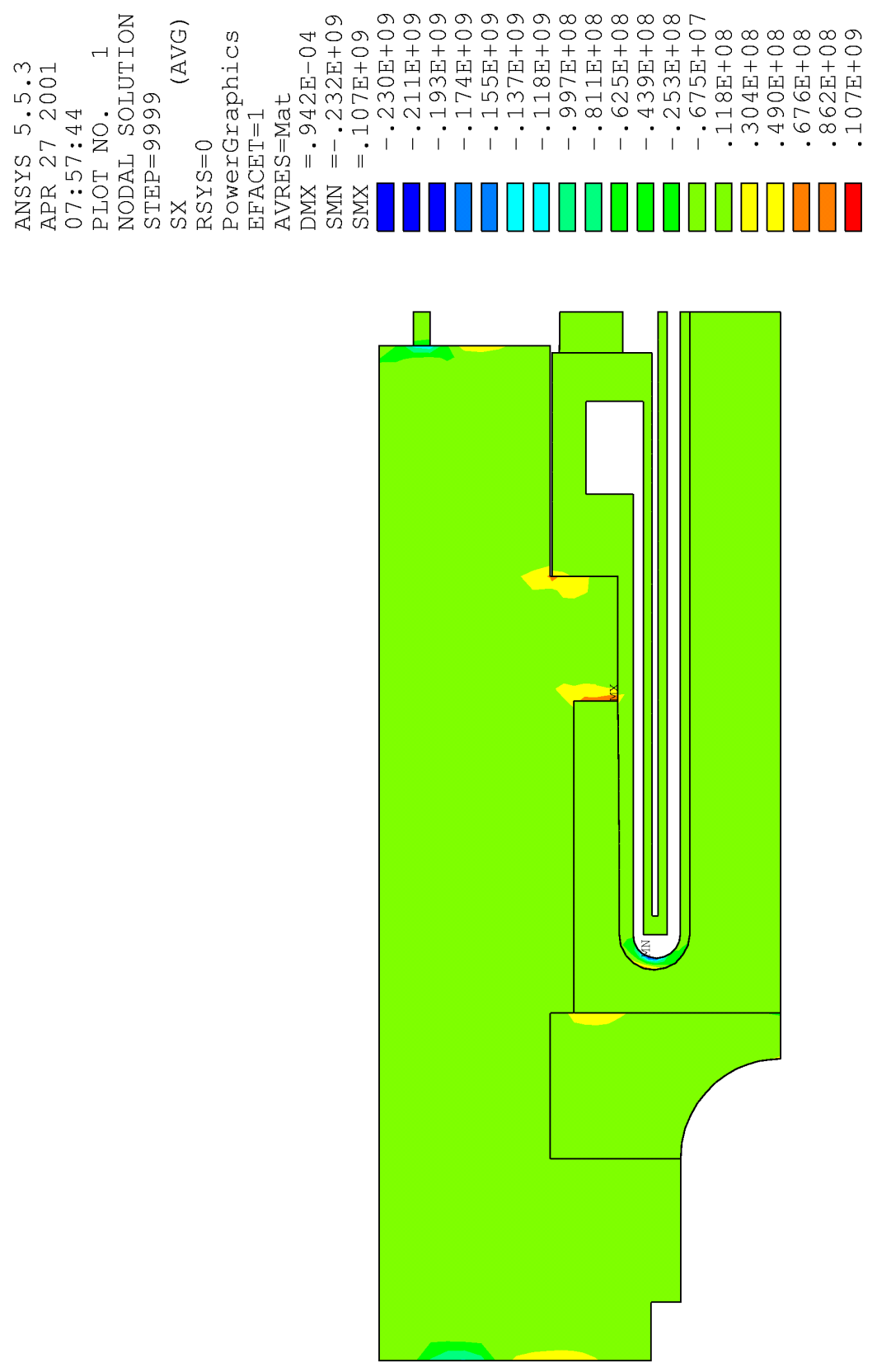

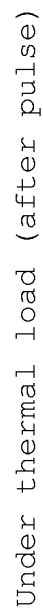

Figure 24. Stress in $\mathrm{X}$ direction (radial) just after pulse (Pa). 

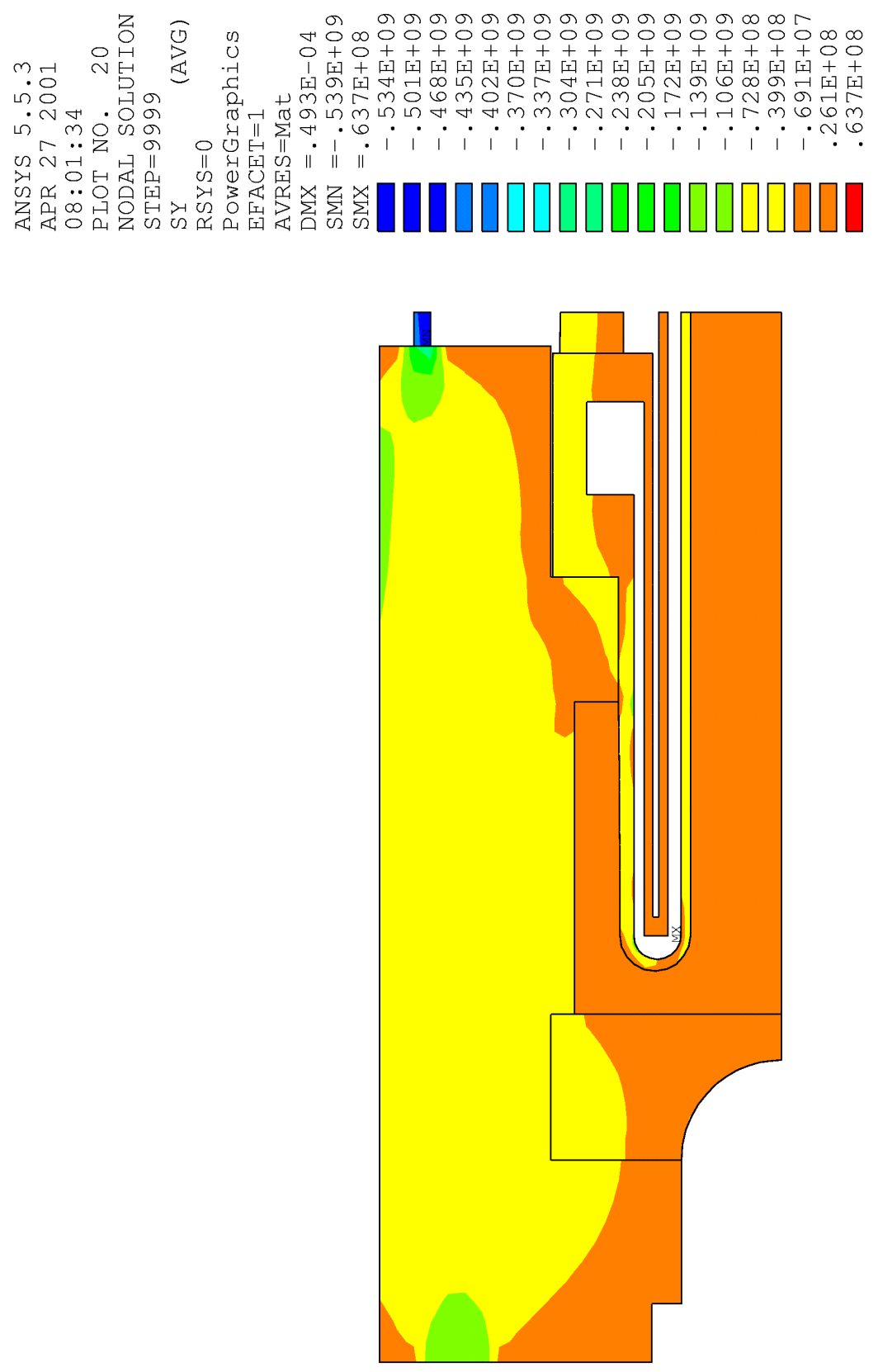

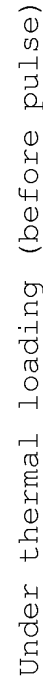

Figure 25. Stress in $\mathrm{Y}$ direction (longitudinal) just before pulse (Pa). 

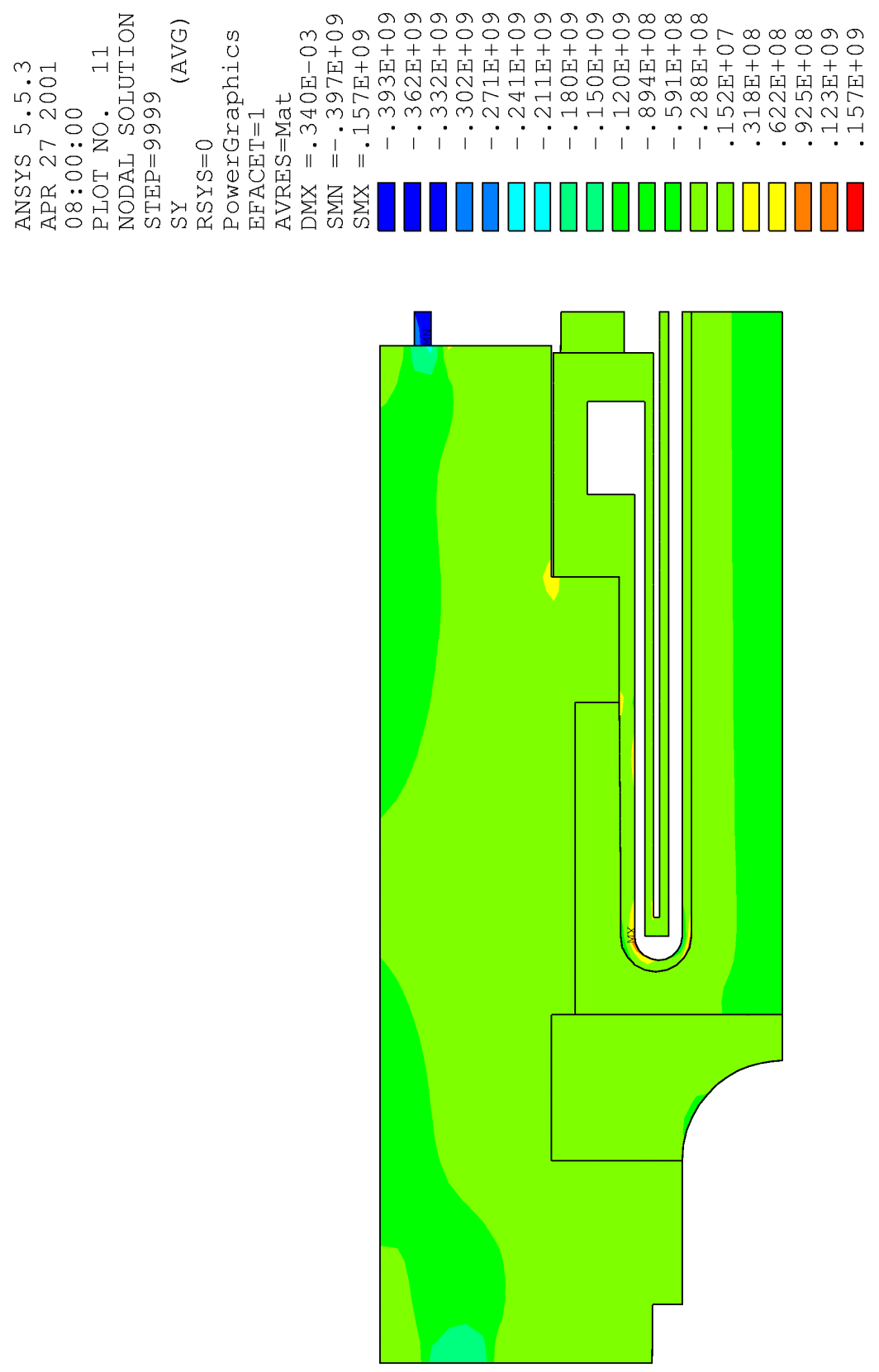

Figure 26. Stress in $\mathrm{Y}$ direction (longitudinal) during pulse $(\mathrm{Pa})$. 

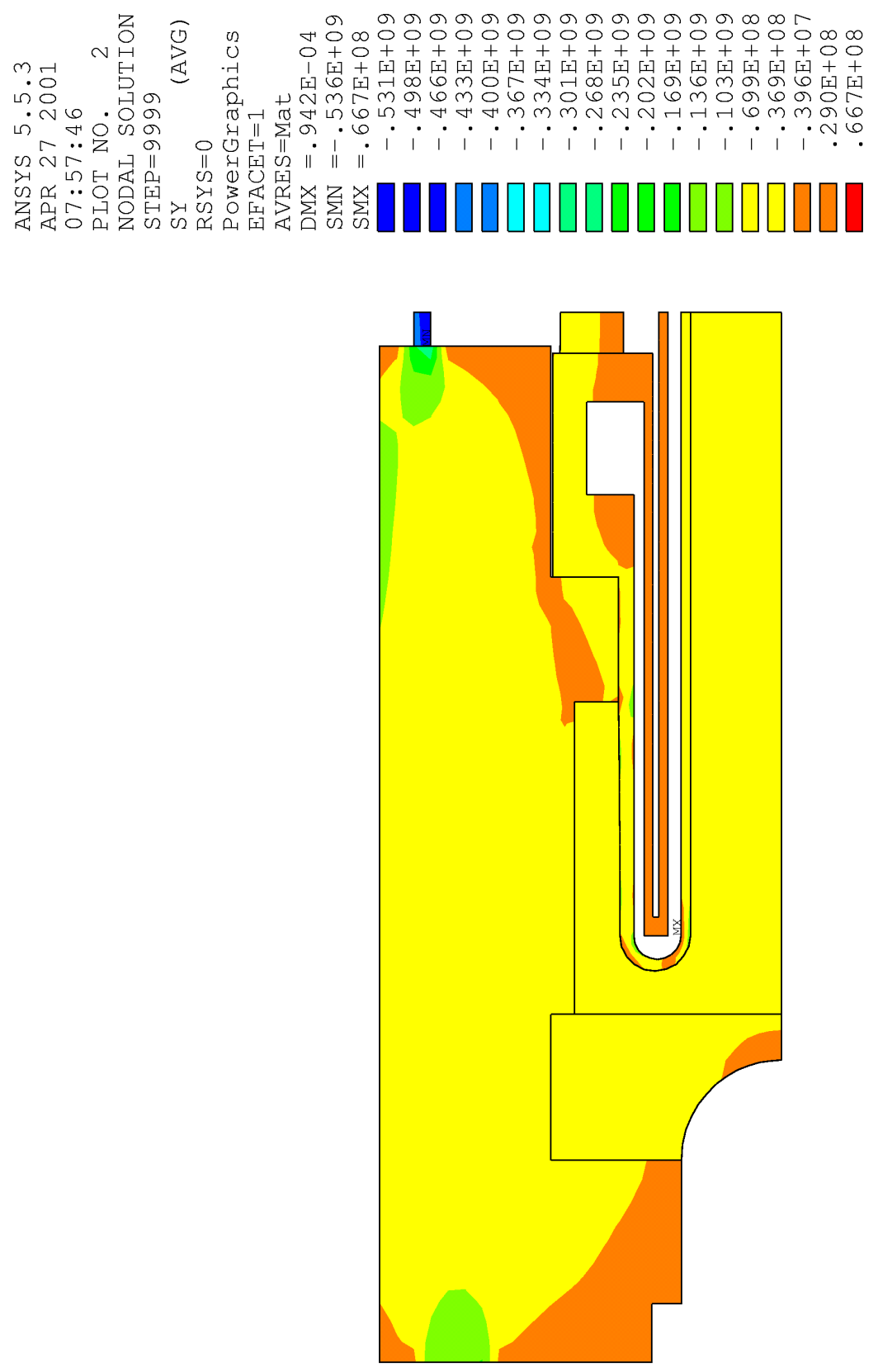

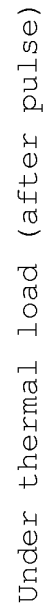

Figure 27. Stress in Y direction (longitudinal) just after pulse (Pa). 

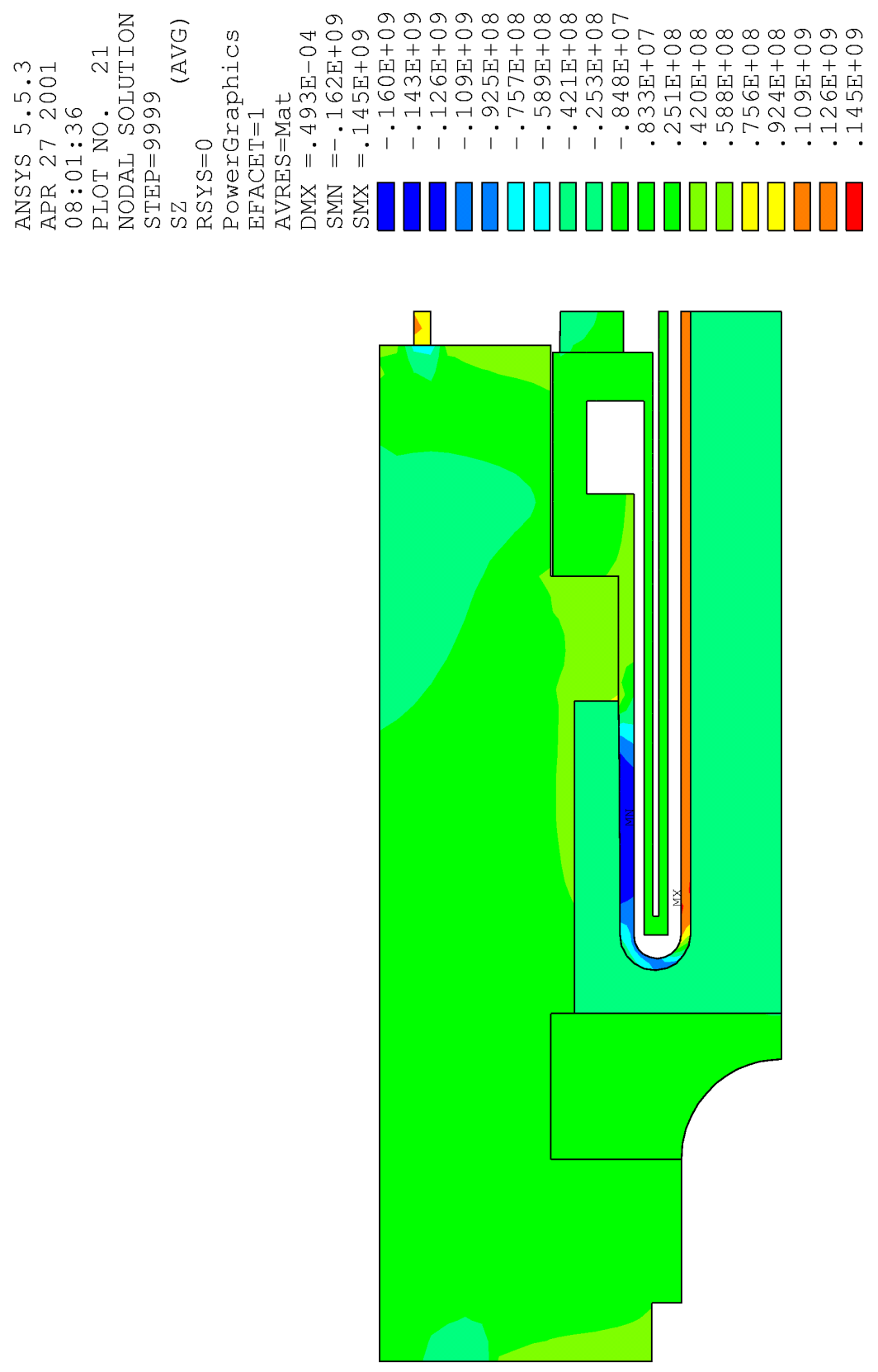

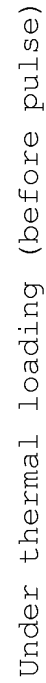

Figure 28. Stress in $\mathrm{Z}$ direction (hoop) just before pulse $(\mathrm{Pa})$. 

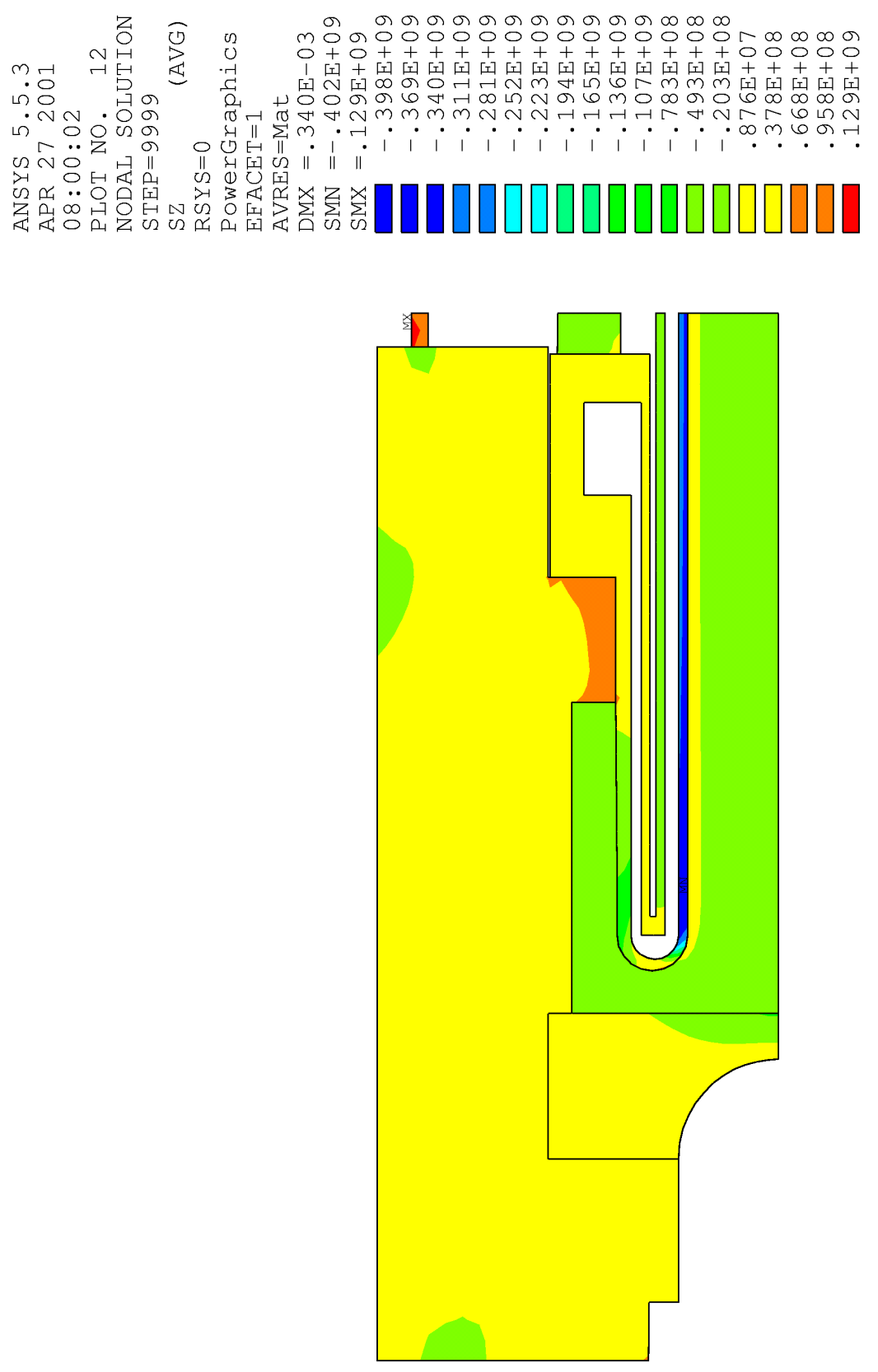

0
0
0
0
0
0
4
7
0
0
4
0
0
0
0
+
1
0
-7
8
0
0
0
0
0
0
0
7
0
-7
0
0
0
0
$\pi$
$\Sigma$

Figure 29. Stress in $\mathrm{Z}$ direction (hoop) during pulse (Pa). 

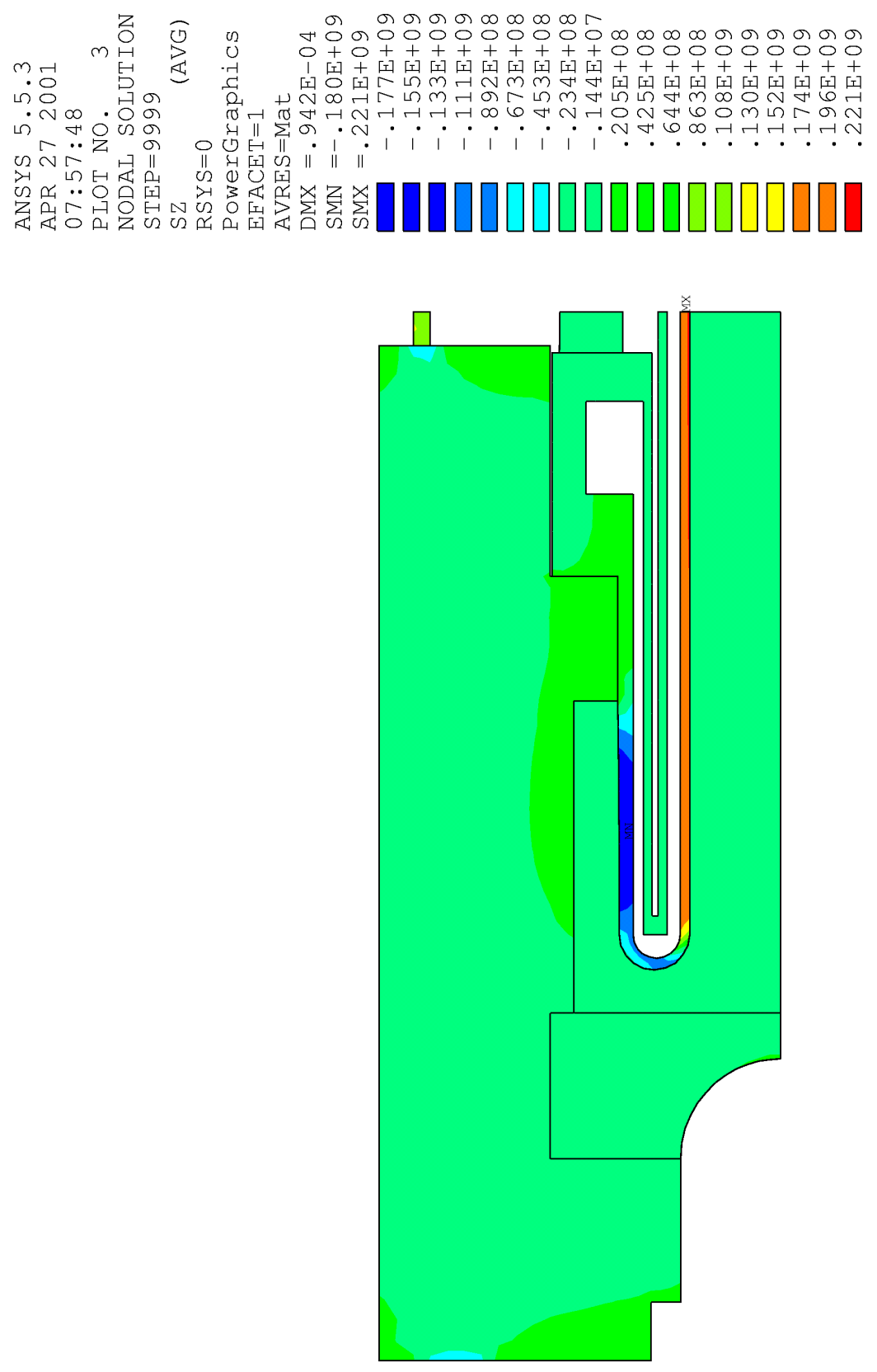

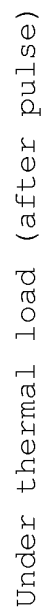

Figure 30. Stress in $\mathrm{Z}$ direction (hoop) just after pulse (Pa). 

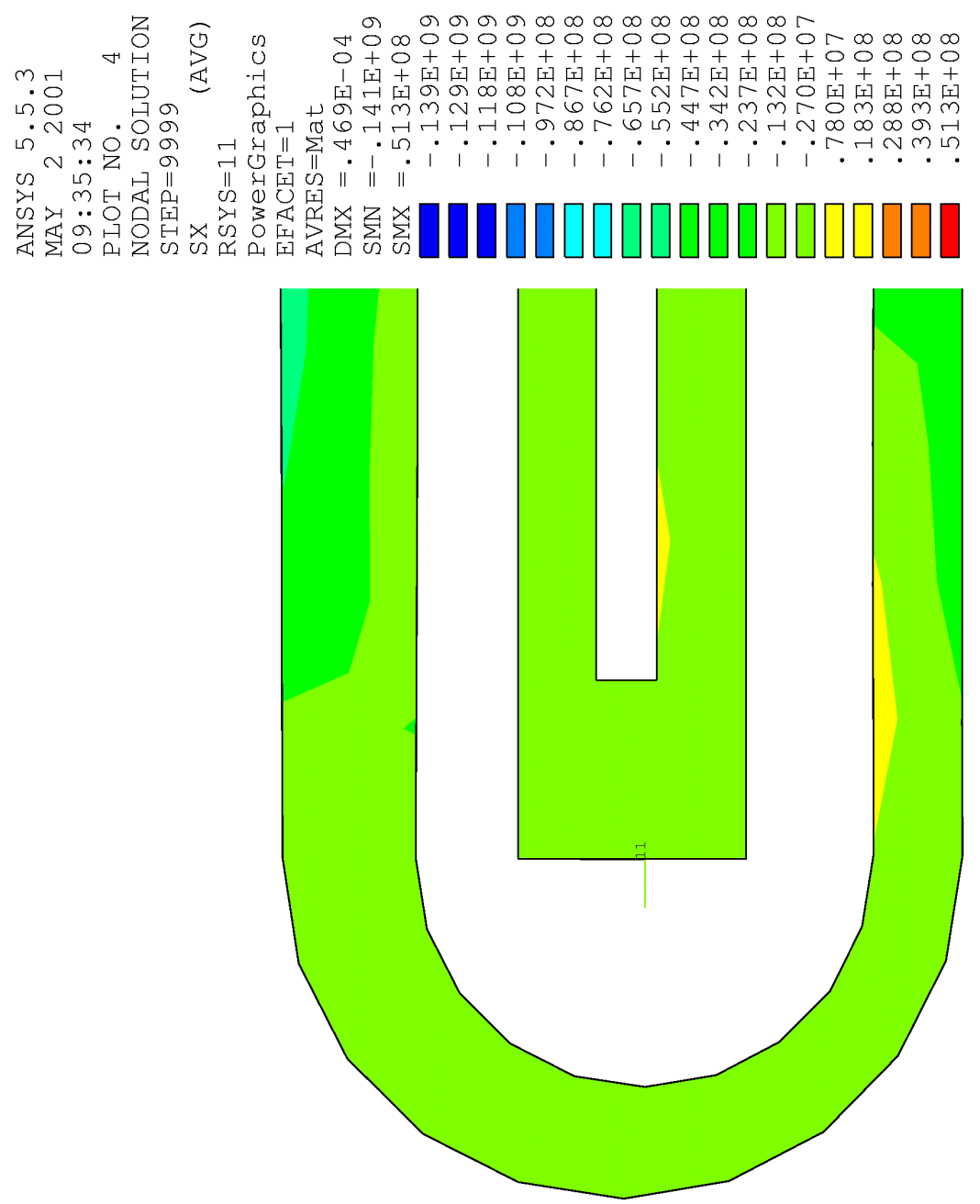

Figure 31. Endcap Stress in $\mathrm{X}$ direction (radial in local coordinate system) just before pulse $(\mathrm{Pa})$. 

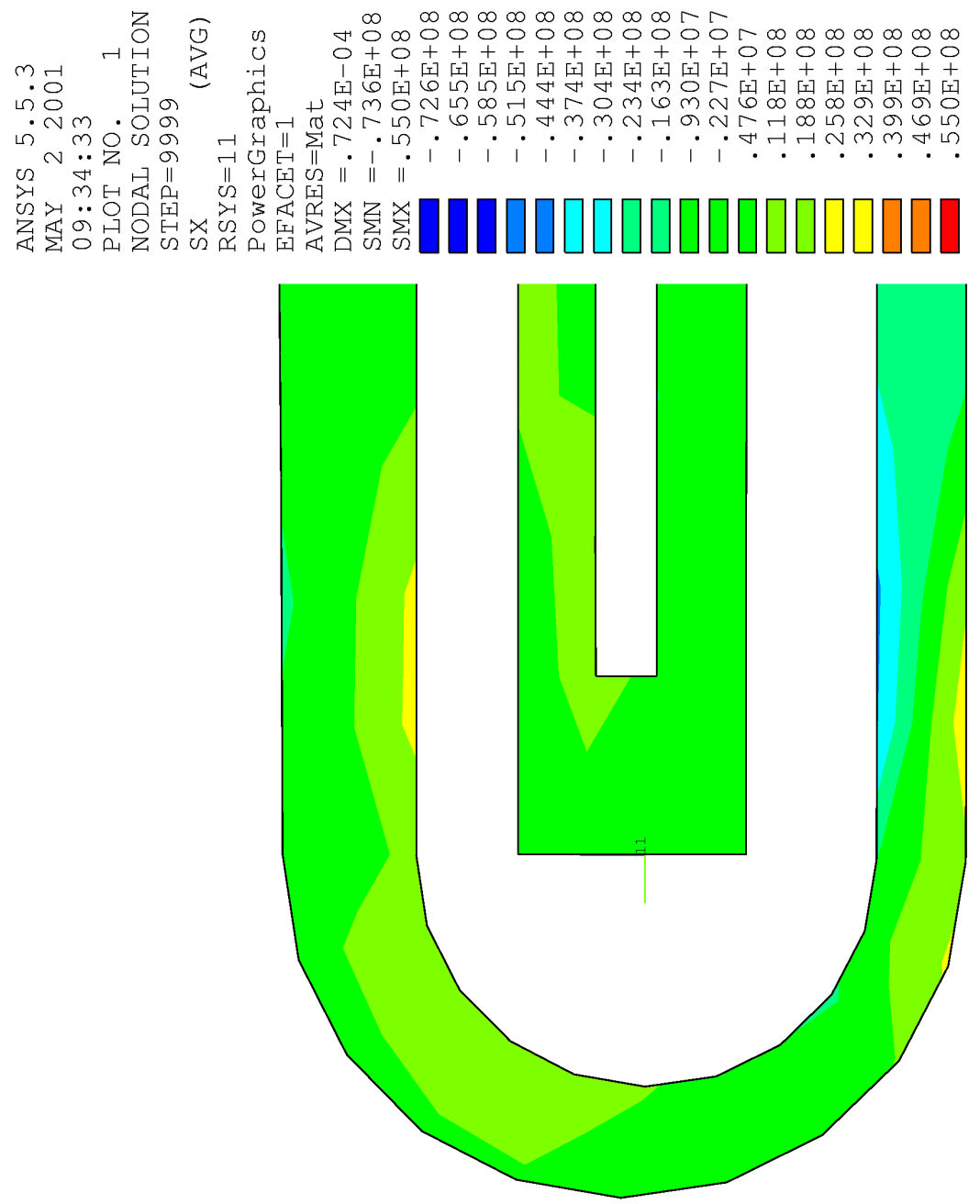

Figure 32. Endcap Stress in X direction (radial in local coordinate system) during pulse $(\mathrm{Pa})$. 

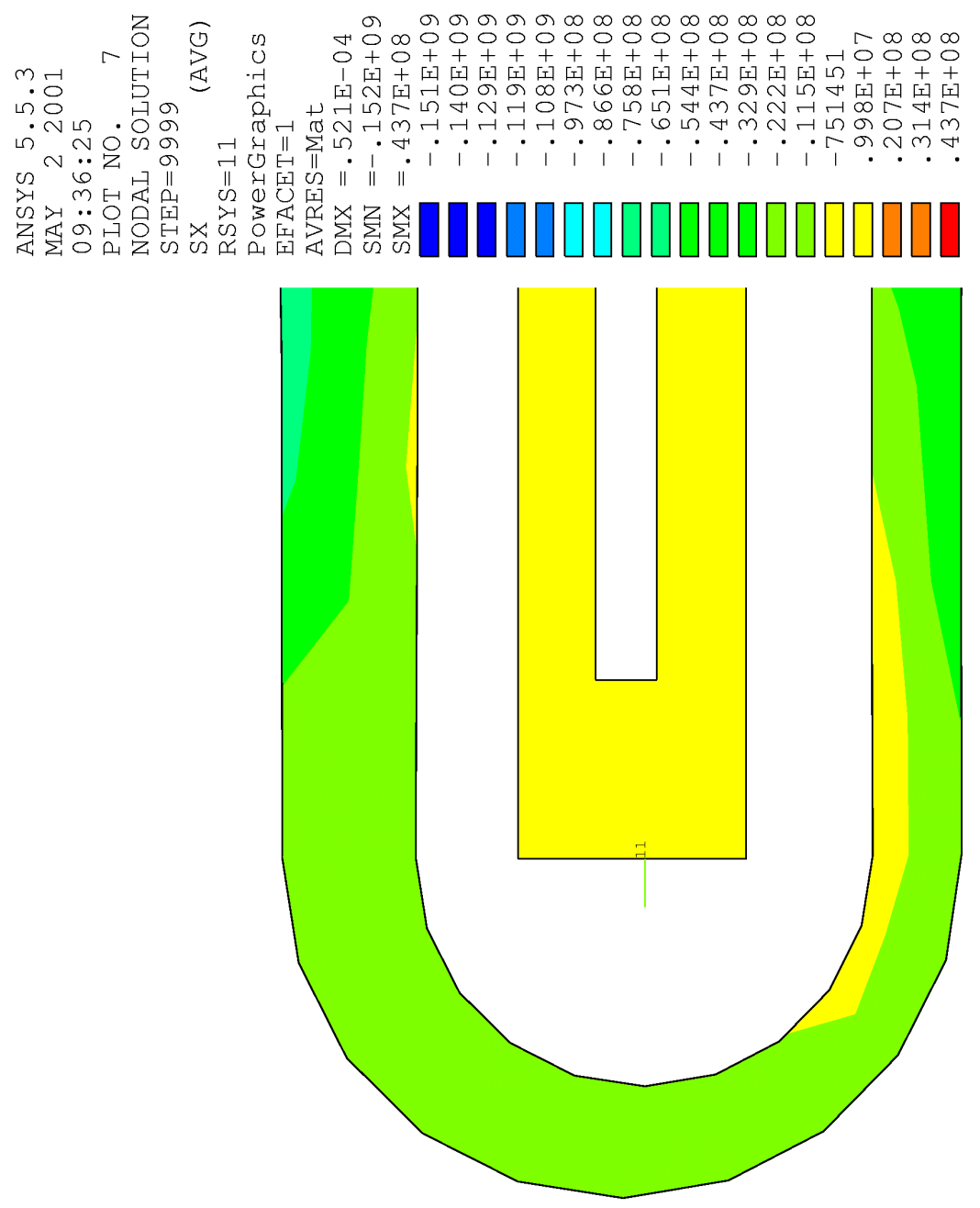

Figure 33. Endcap Stress in X direction (radial in local coordinate system) just after pulse $(\mathrm{Pa})$. 

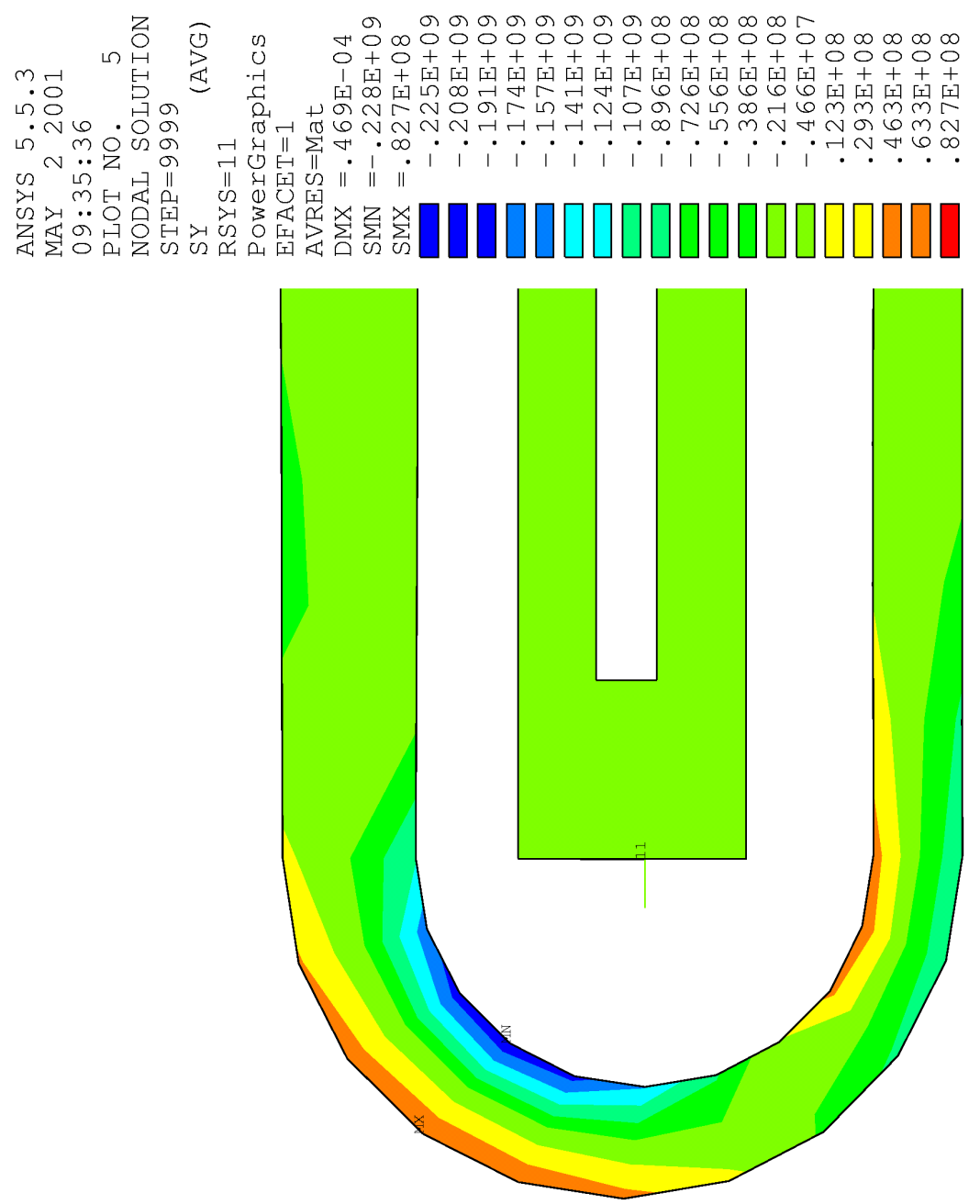

0
0
0
0
7
0
0
0
4
0
0
40
0
0
0
0
0
7
0
0
0
0
7
7
0
0
4
0
0
4
4
4
0
0
C
0

Figure 34. Endcap Stress in Y direction (hoop in local coordinate system) just before pulse $(\mathrm{Pa})$. 

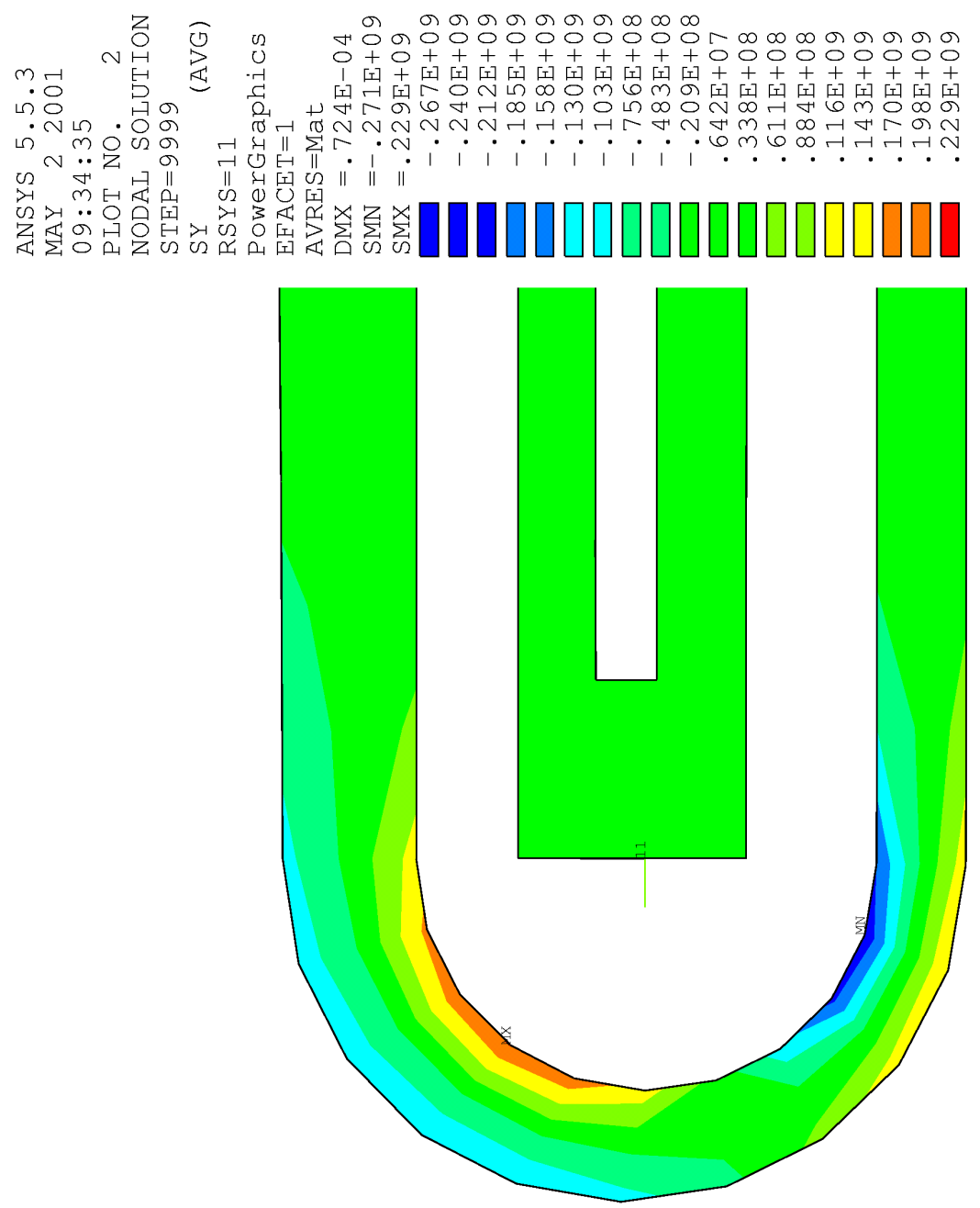

Figure 35. Endcap Stress in Y direction (hoop in local coordinate system) during pulse $(\mathrm{Pa})$. 

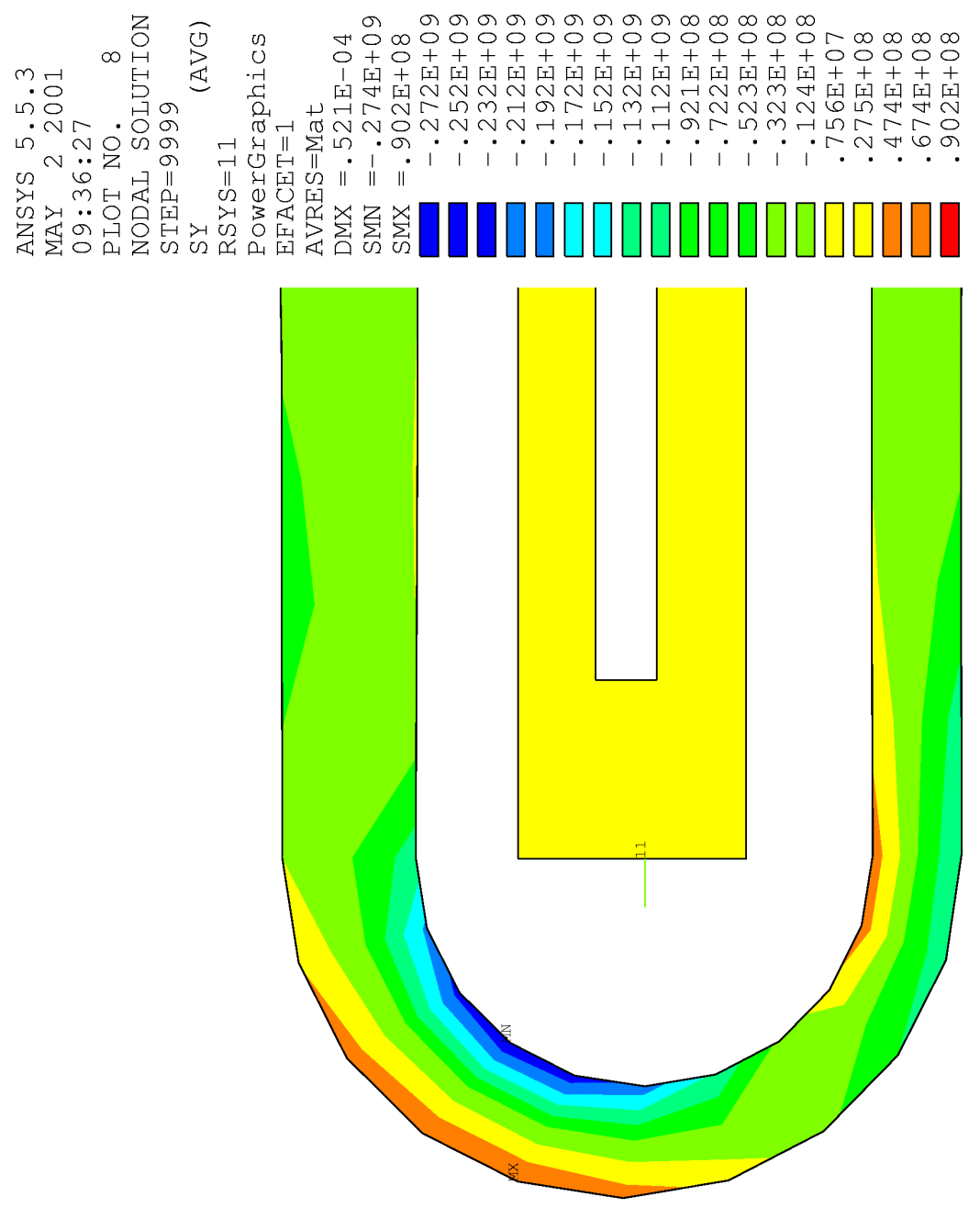

Figure 36. Endcap Stress in Y direction (hoop in local coordinate system) just after pulse $(\mathrm{Pa})$. 

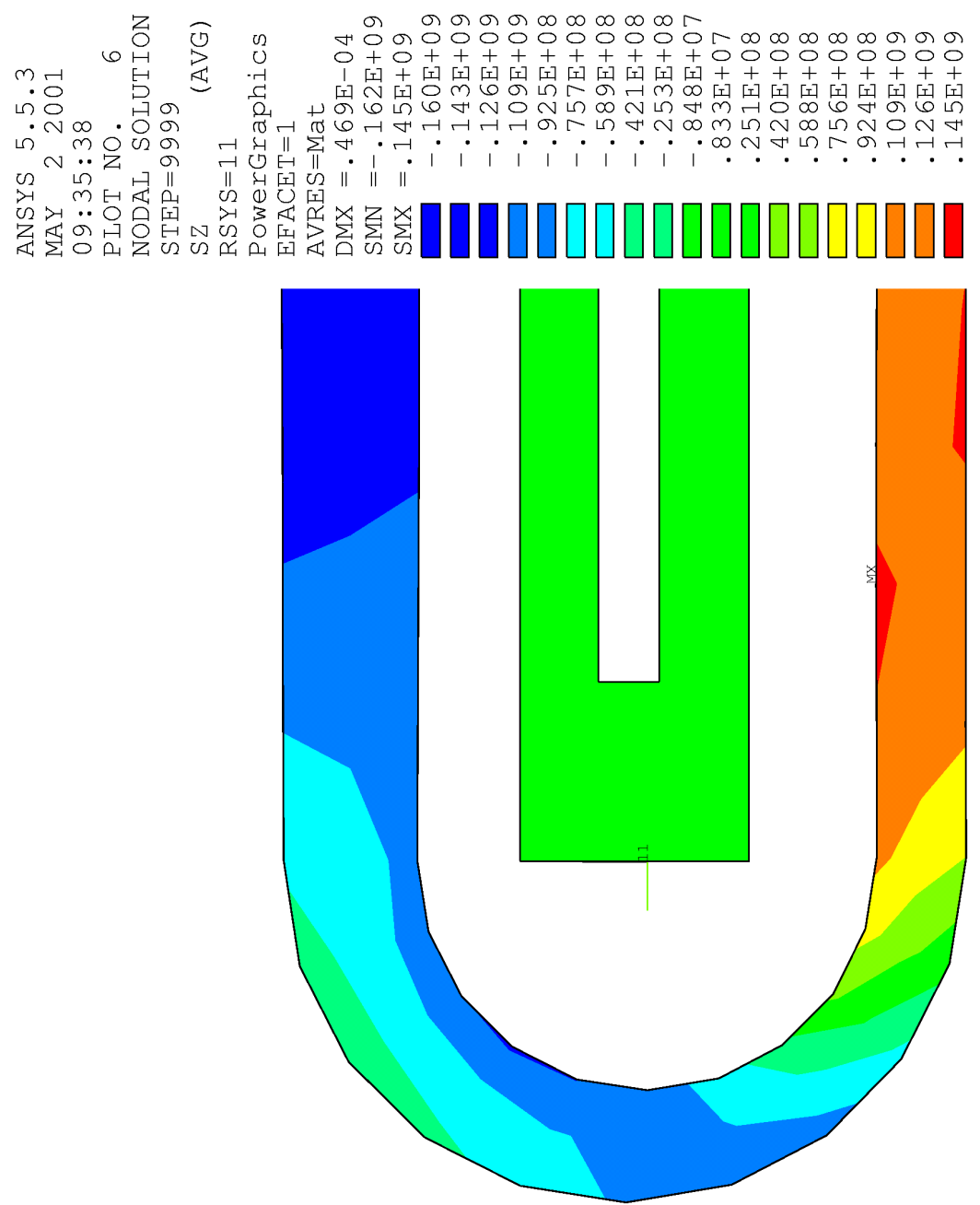

Figure 37. Endcap Stress in $\mathrm{Z}$ direction (hoop in global coordinate system) just before pulse $(\mathrm{Pa})$. 

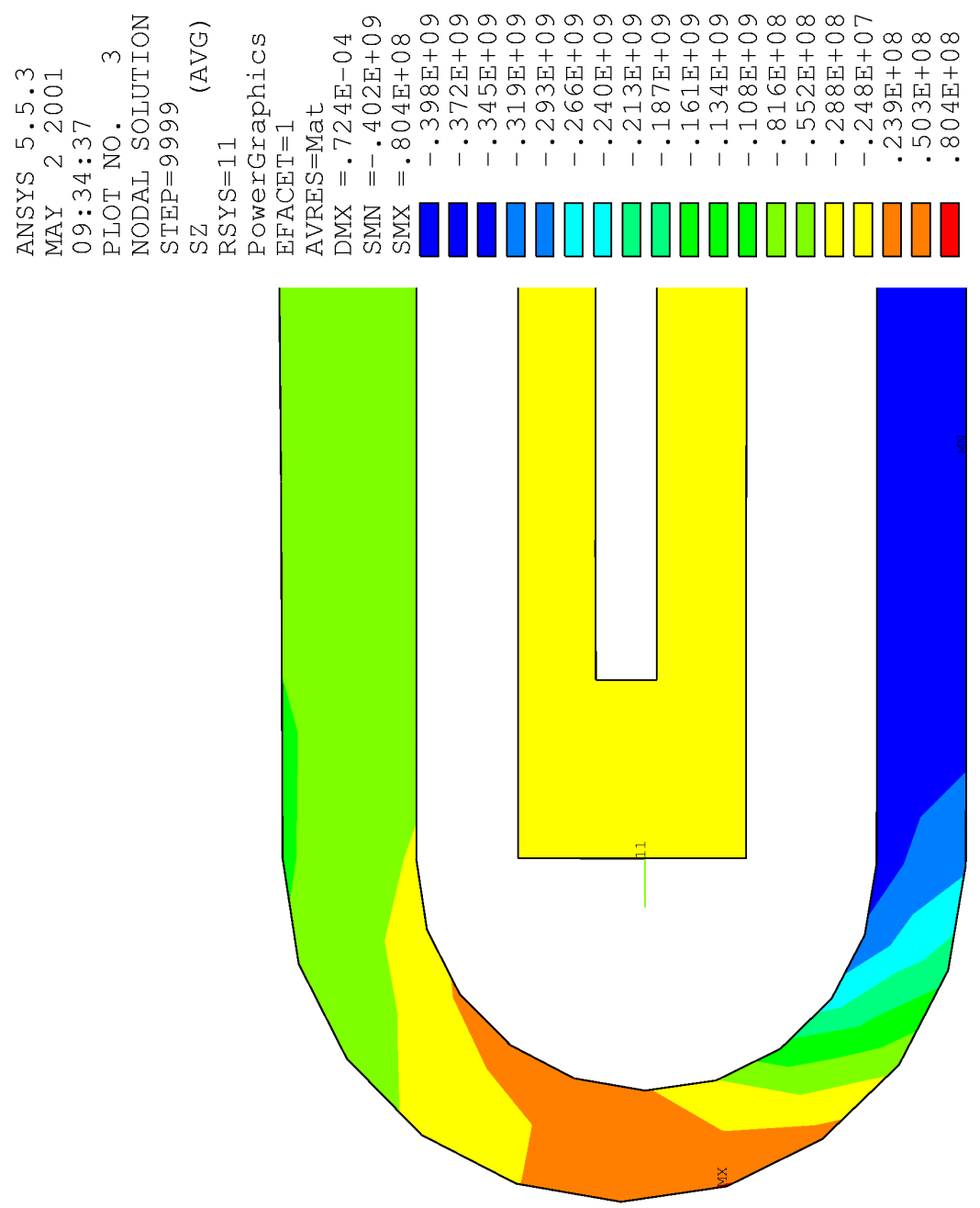

Figure 38. Endcap Stress in $\mathrm{Z}$ direction (hoop in global coordinate system) during pulse $(\mathrm{Pa})$. 

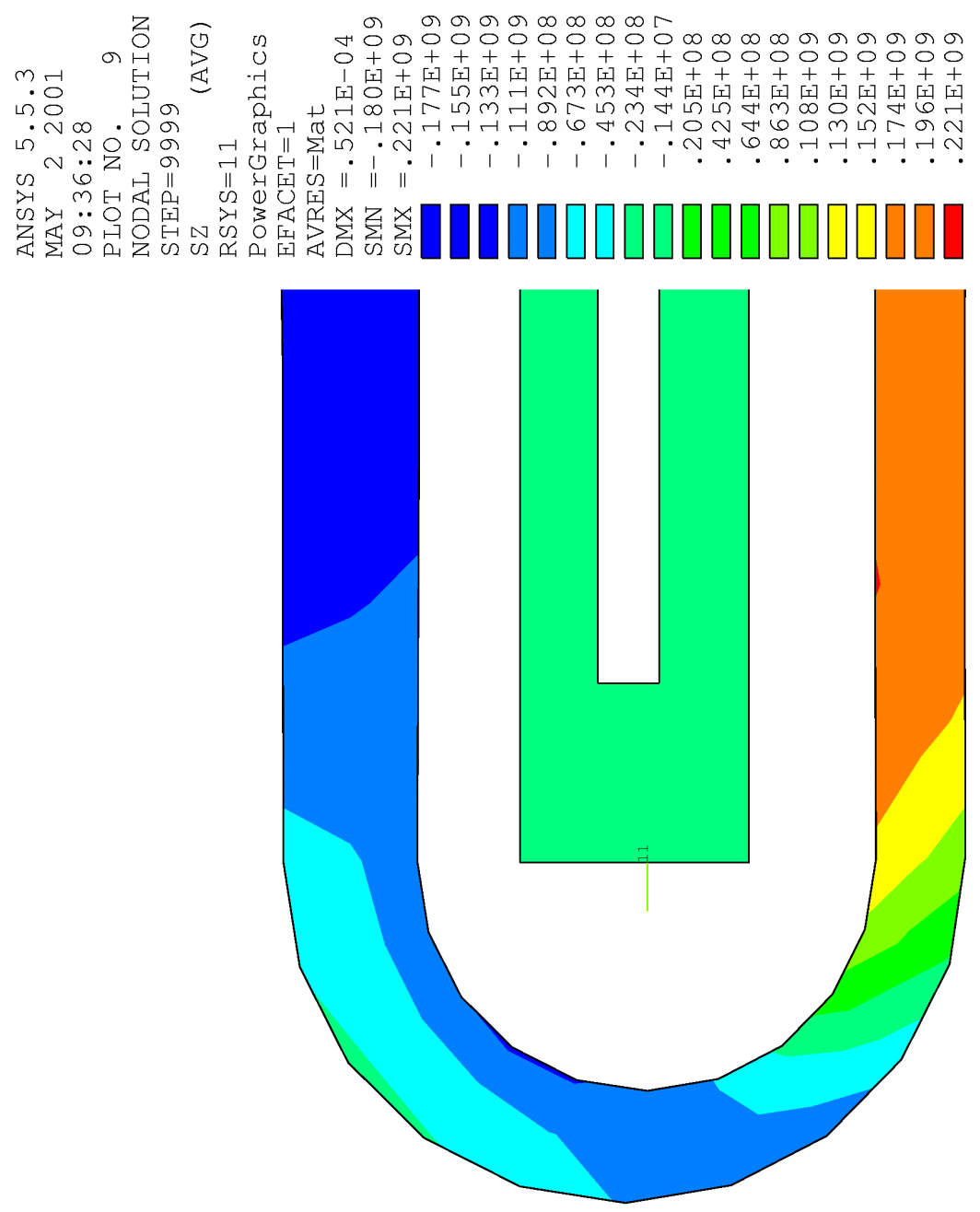

Figure 39. Endcap Stress in $\mathrm{Z}$ direction (hoop in global coordinate system) just after pulse $(\mathrm{Pa})$. 
$\xi$

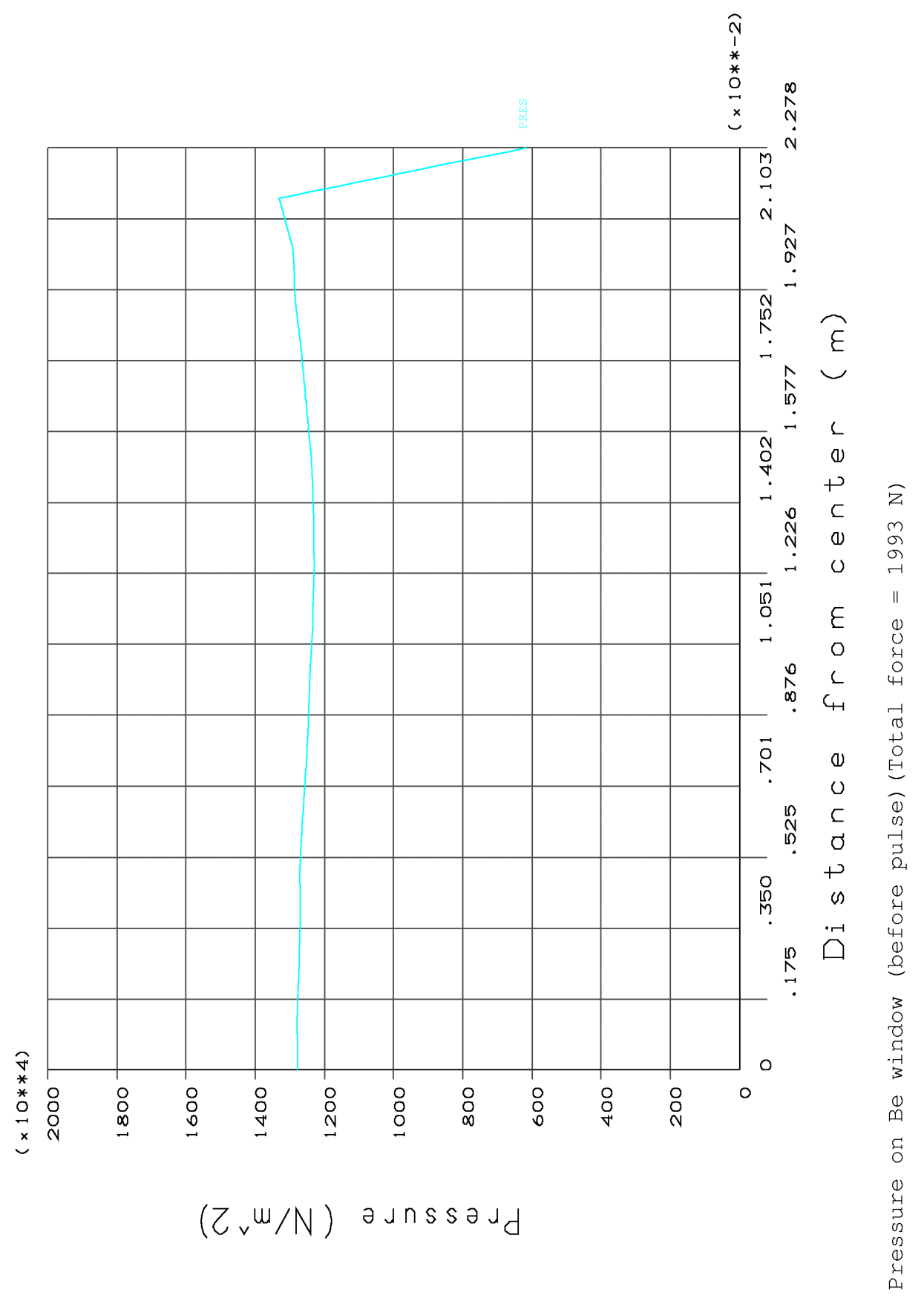

Figure 40. Pressure distribution on Be End Window just before pulse (Pa). 


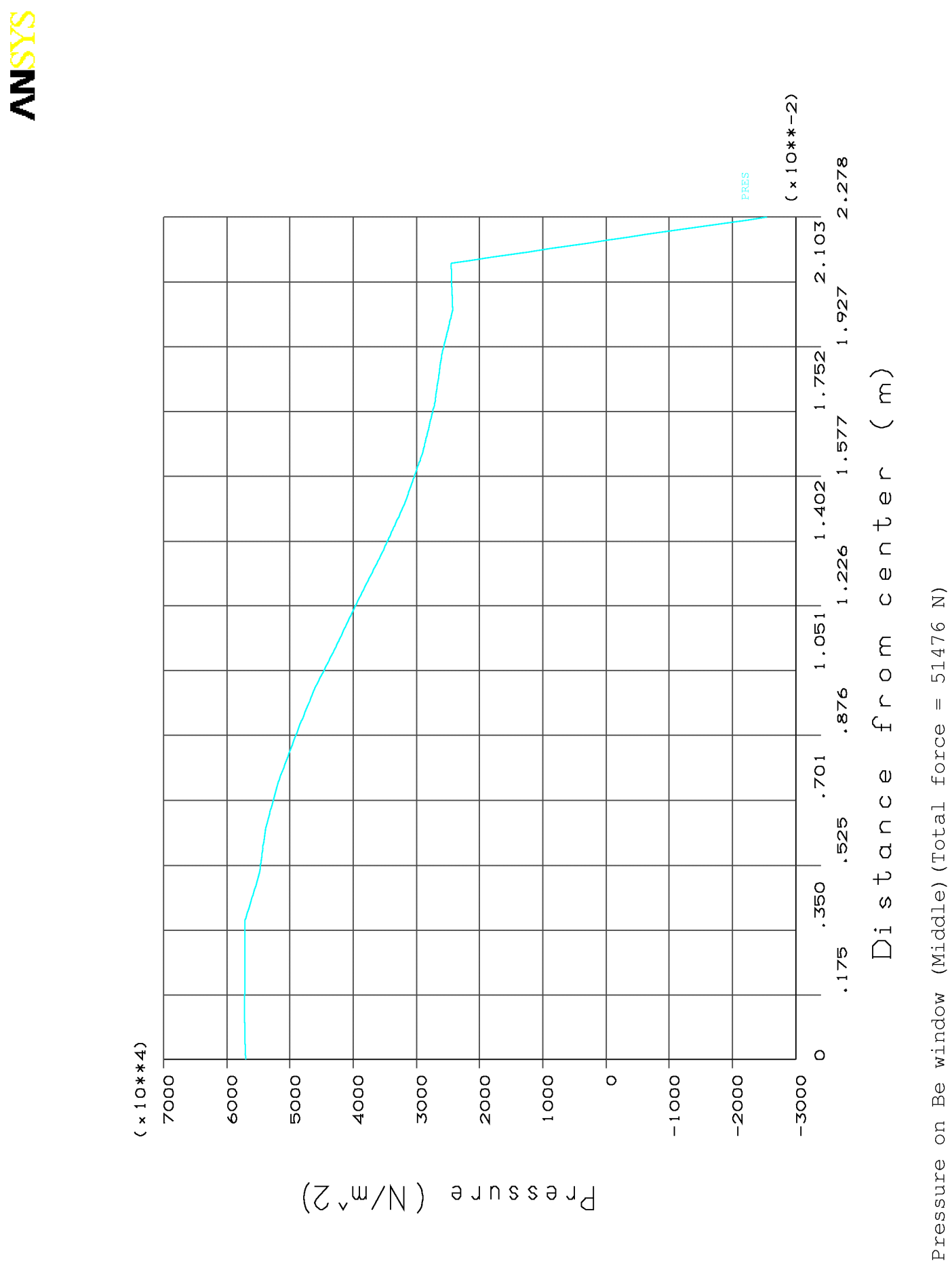

Figure 41. Pressure distribution on Be End Window during pulse (Pa). 


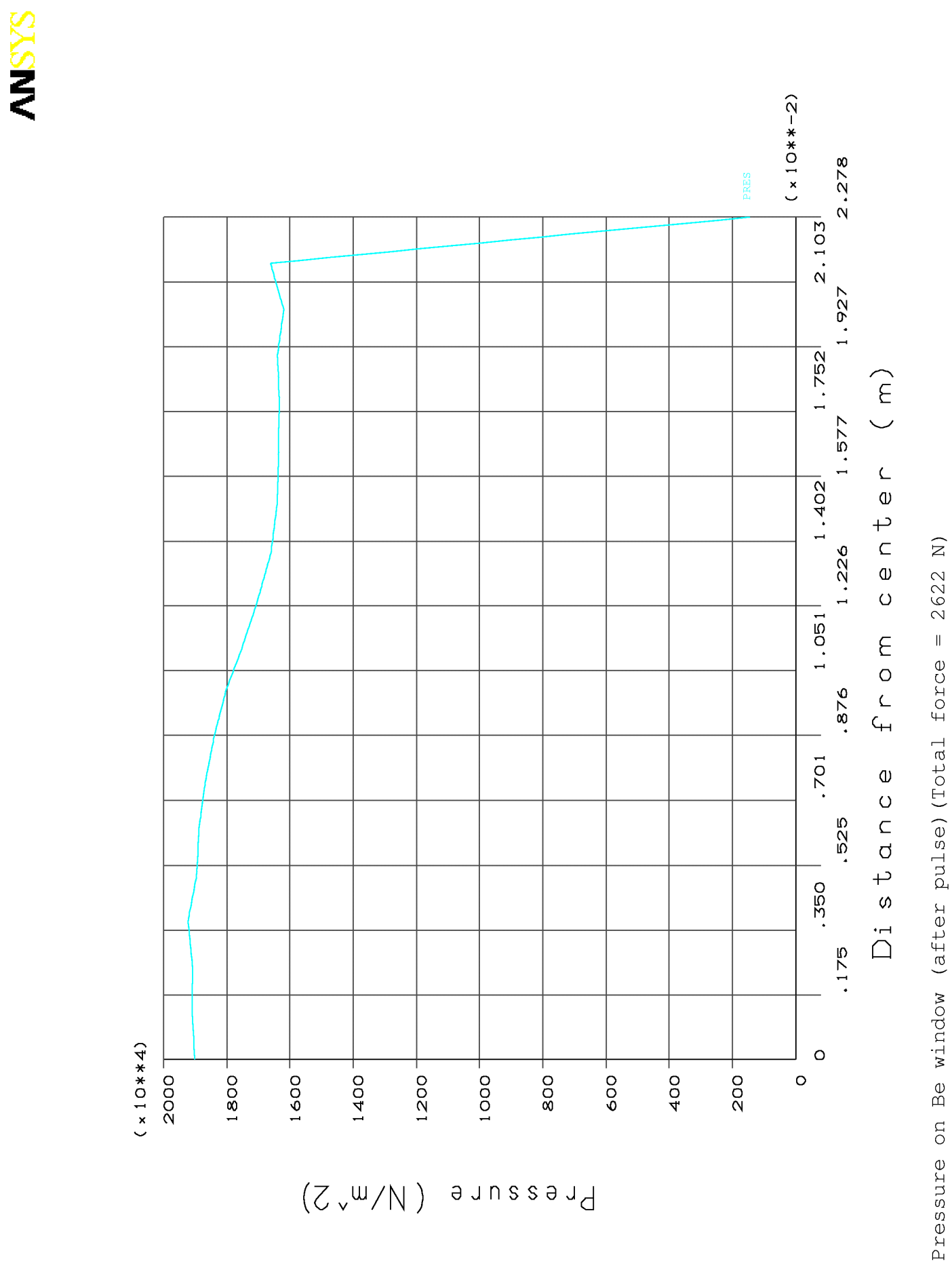

Figure 42. Pressure distribution on Be End Window just after pulse (Pa). 


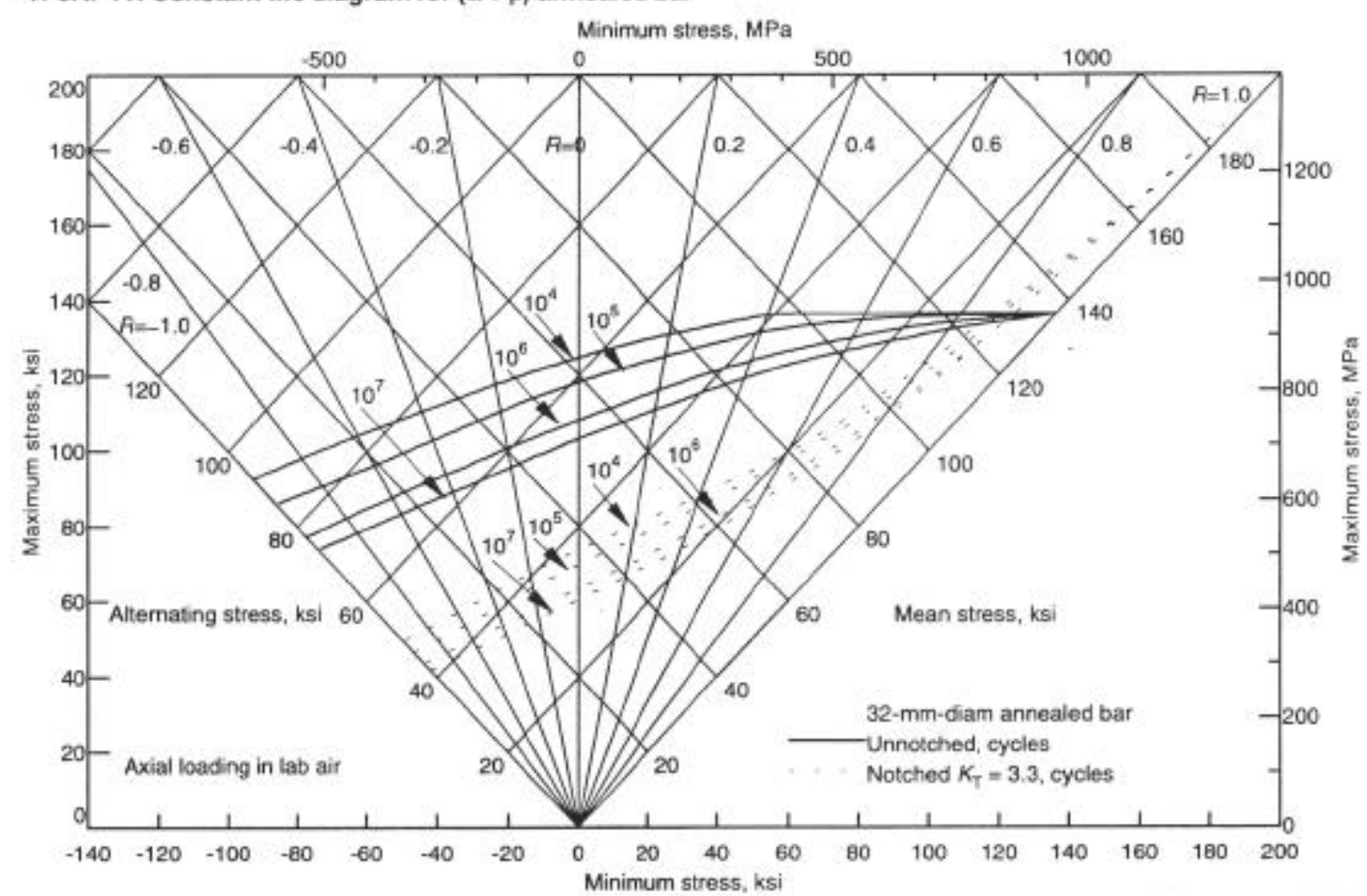

MaterialTest Parameters: Umotched specimen had a 5.15-mm (0.203-in.) dameter, a tensle strength of $940 \mathrm{MPa}$ (136.5 ksi), and was polished longtudinally with 240,400 , and 600 emery belts. Notchod spocimen had a gross diameler of $8.4 \mathrm{~mm}(0.331$ in.), a net diameter of $6.4 \mathrm{~mm}$ ( 0.252 in.), and was machined into a V-groove followed by polishing notch root with 600 -grit shurry and rotating copper wire. Test frequency: 1750 cydes/min.

Source: R. Wood and R. Favor, 7tenium ANloys Handbook, MCIC-HB-02, Battelle Columbus Laboratories, p5-4:72-23

Figure 43. Constant Life Fatigue Diagram. 


\section{Appendix B: \\ Description of Thermal Diffusion Analogy of Magnetic Field}




\begin{tabular}{|c|c|c|c|c|c|}
\hline 类 & $\begin{array}{c}\text { FERMILAB } \\
\text { ENGINEERING NOTE }\end{array}$ & section & Paopect & SERALLCATECOAYY & $\left.\right|^{\text {PNGE }}$, \\
\hline \multirow[t]{2}{*}{ SUDEET } & & & & \multicolumn{2}{|c|}{ NaNE $Z H I J I N G$ TANG } \\
\hline & & & & \multicolumn{2}{|c|}{$\begin{array}{l}\text { DATE } \\
10-4-200 d^{\text {REVISION DATE }}\end{array}$} \\
\hline
\end{tabular}

THERMAL SIMULATION OF MAGNETIC FIELD FOR LITHIUM LENSE

We follow the idew of $I_{j}$ speert and sievers

(Cern SPS/ABT/AI/BC/Tech note 86-2), use thermal

simulation to solve the magnetic field of the lithium lense.

1. Basic equations

From Maxwell equations

$$
\begin{array}{ll}
\nabla \cdot \vec{D}=0 & \vec{D}=\varepsilon \vec{E} \\
\nabla \cdot \vec{B}=0 & \vec{B}=\mu \vec{H} \\
\nabla \times \vec{E}=-\partial \vec{B} / \partial t & \vec{J}=\nabla \vec{E} \\
\nabla \times \vec{H}=\vec{J}+\partial \vec{D} / \partial t &
\end{array}
$$

Here $\partial \vec{D} / \partial t$ cam be neflected componed with $\vec{j}$ (App I) Assume matenial properties to be constants, We cam write

$$
\begin{aligned}
& \mu \frac{\partial \vec{H}}{\partial t}=-\nabla \times \vec{E}=-\sigma \nabla \times(\nabla \times \vec{H})=\sigma \nabla^{2} \vec{H} \\
& \text { (since } \nabla \times(\nabla \times \vec{H})=\nabla(\nabla \cdot \vec{H})-\nabla^{2} \vec{H} \text {, and } \nabla \cdot \vec{H}=0 \text { ) }
\end{aligned}
$$

In our problem $\vec{H}=H \vec{e}_{\varphi}$

$$
\nabla^{2} \vec{H}=\left(\nabla^{2} H-\frac{1}{r^{2}} H\right) \vec{e}_{\varphi}
$$

Equation becomes

$$
\mu \frac{\partial H}{\partial t}=\left(\frac{\partial^{2} H}{\partial r^{2}}+\frac{1}{r} \frac{\partial H}{\partial \gamma}-\frac{H}{r^{2}}+\frac{\partial^{2} H}{\partial z^{2}}\right) \sigma
$$




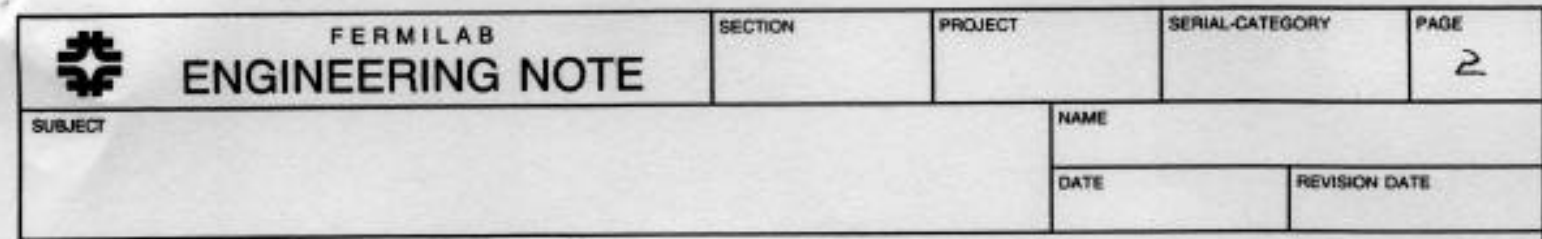

In order to compone with heat trancfer equation.

We write it as

$$
\frac{\mu}{r} \frac{\partial(r H)}{\partial t}=\frac{\partial}{\partial r}\left[\frac{\sigma}{r} \frac{\partial(r H)}{\partial r}\right]+\frac{\partial}{\partial z}\left[\frac{\sigma}{r} \frac{\partial(r H)}{\partial z}\right]
$$

2. Thermal simulation

Compace equation (4) with 2-D heat transfer equation

$$
\rho c \frac{\partial T}{\partial t}=\frac{\partial}{\partial r}\left(k \frac{\partial T}{\partial r}\right)+\frac{\partial}{\partial z}\left(k \frac{\partial T}{\partial z}\right)
$$

We have following simularity

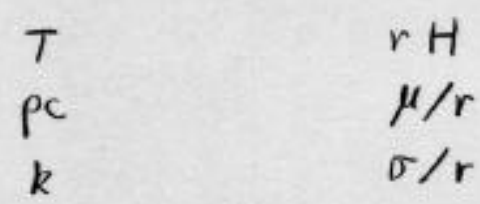

After solve heat transfer problem in 2-D Coutisian coordinates. We can get following solution for masnetic problem in cylindrical coordinates:

magnetic field strength

current density

joule heat

Lorente force $\vec{f}=\vec{j} \times \vec{B}$

$$
\begin{aligned}
& H-\frac{1}{r} T \\
& j_{r}-\frac{1}{r}(\nabla T)_{z} \\
& j_{z}-\frac{1}{r}(\nabla T)_{r} \\
& u-\frac{k}{r}(\nabla T)^{2} \\
& --\frac{\mu}{r^{2}} T \nabla T
\end{aligned}
$$




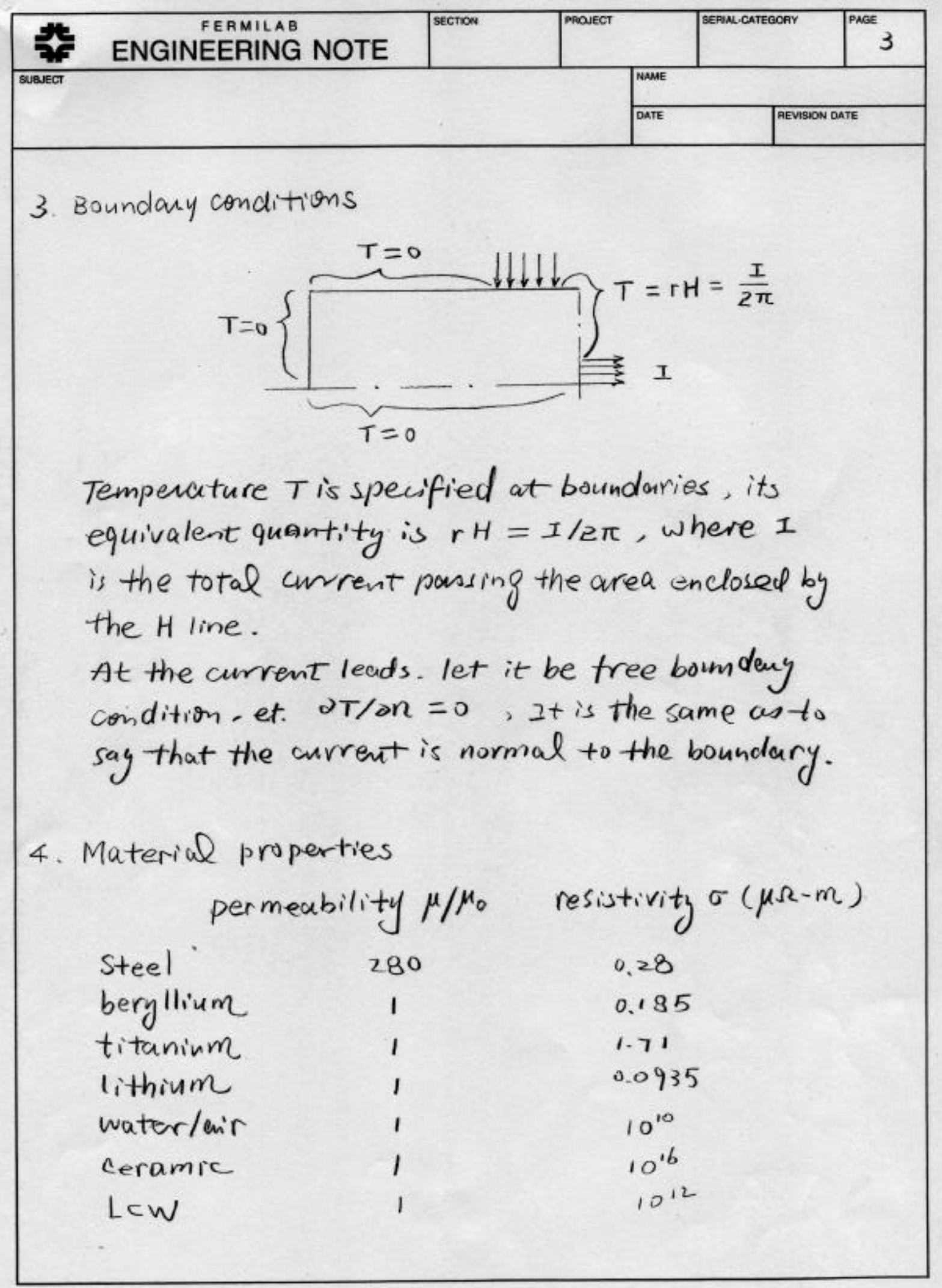


Appendix C:

Tables 


\begin{tabular}{|c|c|c|c|c|c|c|c|}
\hline & Steel & Beryllium & Titanium & $\begin{array}{l}\text { Lithium } \\
\end{array}$ & Water & Air & Ceramic \\
\hline $\begin{array}{l}\text { Resistivity } \\
\left(10^{-8} \text { ?-m) }\right.\end{array}$ & 28 & 18.5 & 171 & 9.35 & $10^{6}$ & $10^{18}$ & $10^{24}$ \\
\hline $\begin{array}{c}\text { Permeability } \\
\text { (relative) }\end{array}$ & 280 & 1 & 1 & 1 & 1 & 1 & 1 \\
\hline $\begin{array}{l}\text { Saturation } \\
(\mathrm{A} / \mathrm{m})\end{array}$ & $10^{4}$ & & & & & & \\
\hline $\begin{array}{l}\text { Density } \\
\left(\mathrm{kg} / \mathrm{m}^{3}\right) \\
\end{array}$ & 7800 & 1850 & 4430 & 534 & & & 2000 \\
\hline $\begin{array}{c}\text { Specific Heat } \\
\text { (J/Kg-C) }\end{array}$ & 452 & 2170 & 580 & 3515 & & & 500 \\
\hline $\begin{array}{l}\text { Conductivity } \\
\text { (w/m-C) }\end{array}$ & 43 & 145 & 125 & 75 & & & 10 \\
\hline $\begin{array}{c}\mathrm{CTE} \\
\left(10^{6} \mathrm{C}^{-1}\right)\end{array}$ & 11.9 & 12.3 & 9.0 & 50 & & & 5.0 \\
\hline $\begin{array}{c}\text { Elastic } \\
\text { Modulus } \\
\left(10^{9} \mathrm{~N} / \mathrm{m}^{2}\right)\end{array}$ & 207 & 303 & 110 & $\begin{array}{l}1.9 \\
(.095)\end{array}$ & & & 303 \\
\hline $\begin{array}{l}\text { Poisson's } \\
\text { Ratio }\end{array}$ & .29 & .12 & .33 & .38 & & & .2 \\
\hline
\end{tabular}

Table 1: Material Properties used in ANSYS simulation.

Energy Deposition in Ni Target and Collection Lens Body by Material

\begin{tabular}{|c|c|c|c|c|c|c|c|c|c|c|}
\hline & & \multicolumn{3}{|c|}{ Target Totals (GeV per pulse) } & \multicolumn{4}{|c|}{ CASIM066 CASIM067 CASIM068 Average } & & \\
\hline & & & & Nickel & $850=-01$ & 8.40E-01 & 8.63E-01 & 8.51E-01 & & \\
\hline \multicolumn{11}{|c|}{ Total Energy in Joules per pulse } \\
\hline & Steel & Water & Lithium & Titanium & Nickel & Beryllium & Lithium & Lithium & Lithium & Field \\
\hline & MAT \#1 & MAT \#2 & MAT \#3 & MAT \#4 & MAT \#5 & MAT \#6 & MAT \#7 & MAT \#8 & MAT \#9 & (TESLA) \\
\hline CASIM066 & $1.26 \mathrm{E}+03$ & $2.94 \mathrm{E}+01$ & $2.84 \mathrm{E}+01$ & $2.58 \mathrm{E}+02$ & $6.80 \mathrm{E}+02$ & $5.00 E+01$ & $7.08 \mathrm{E}+00$ & $6.03 E+00$ & $5.64 \mathrm{E}+00$ & 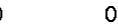 \\
\hline CASIM067 & $71.21 \mathrm{E}+03$ & $3.05 \mathrm{E}+01$ & $2.78 \mathrm{E}+01$ & $2.62 \mathrm{E}+02$ & $6.72 \mathrm{E}+02$ & $4.74 \mathrm{E}+01$ & $7.00 \mathrm{E}+00$ & $5.25 \mathrm{E}+00$ & $5.68 \mathrm{E}+00$ & -10 \\
\hline CASIM068 & $31.25 \mathrm{E}+03$ & $3.00 \mathrm{E}+01$ & $2.83 E+01$ & $2.51 \mathrm{E}+02$ & $6.91 E+02$ & $4.88 \mathrm{E}+01$ & $6.80 E+00$ & $5.74 \mathrm{E}+00$ & $4.80 E+00$ & 10 \\
\hline
\end{tabular}

Lens Totals (Joules per pulse) CASIM066 CASIM067 CASIM068 Average

$\begin{array}{lllll}\text { Lithium } & 4.71 \mathrm{E}+01 & 4.57 \mathrm{E}+01 & 4.56 \mathrm{E}+01 & 4.61 \mathrm{E}+01\end{array}$

Steel $\quad 1.26 \mathrm{E}+03 \quad 1.21 \mathrm{E}+03 \quad 1.25 \mathrm{E}+03 \quad 1.24 \mathrm{E}+03$

Water 2.94E+01 3.05E+01 3.00E+01 3.00E+01

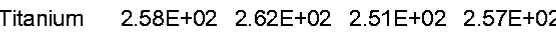

Beryllium 5.00E+01 4.74E+01 4.88E+01 $4.88 \mathrm{E}+01$

Total 1.62E+03

Target Totals (Joules per pulse) CASIM066 CASIM067 CASIM068 Average

Nickel
Average Power 5E12 protons every 1.5 seconds $3.08 \mathrm{E}+01$ Watts 8.27E+02 Watts

$2.00 \mathrm{E}+01$ Watts

1.71E+02 Watts

$3.25 \mathrm{E}+01$ Watts

$1.08 \mathrm{E}+03$ Watts

Average Power $5 E 12$ protons every 1.5 seconds $4.54 \mathrm{E}+02$ Watts

Table 2: CASIM results used for beam heating in ANSYS simulation. 


\begin{tabular}{|c|c|}
\hline Water Cooling & $12,500 \mathrm{w} / \mathrm{m}^{2}-\mathrm{K}$ \\
\hline Convective Cooling & $4 \mathrm{w} / \mathrm{m}^{2}-\mathrm{K}$ \\
\hline $\begin{array}{c}\text { Conductive Cooling } \\
\text { (thermal resistance of transformer } \\
\text { fingers heat sunk at } 22^{\circ} \mathrm{C} \text { ) }\end{array}$ & $0.47 \mathrm{~K} / \mathrm{w}$ \\
\hline
\end{tabular}

Table 3: Cooling Load parameters used in ANSYS simulation.

\begin{tabular}{|c|c|c|c|c|c|}
\hline & $\begin{array}{c}\text { Maximum } \\
\text { Stress } \\
\text { Pa (ksi) }\end{array}$ & $\begin{array}{c}\text { Minimum } \\
\text { Stress } \\
\text { Pa (ksi) }\end{array}$ & $\begin{array}{c}\text { Fatigue } \\
\text { Ratio } \\
(\mathrm{min} / \mathrm{max})\end{array}$ & $\begin{array}{c}\text { Endurance Limit } \\
(\mathrm{R}=-1) \\
\text { Pa (ksi) }\end{array}$ & $\begin{array}{c}\text { Factor of } \\
\text { Safety }\end{array}$ \\
\hline $\begin{array}{c}\text { Inner } \\
\begin{array}{c}\text { Conductor } \\
\text { Tube }\end{array}\end{array}$ & $\begin{array}{c}0.221 \mathrm{E} 9 \\
(32.1)\end{array}$ & $\begin{array}{c}-0.398 \mathrm{E} 9 \\
(-57.7)\end{array}$ & -1.8 & $\begin{array}{c}0.396 \mathrm{E} 9 \\
(57.5)\end{array}$ & 1.8 \\
\hline $\begin{array}{c}\text { Outer Radius } \\
\text { of Endcap }\end{array}$ & $\begin{array}{c}0.159 \mathrm{E} 9 \\
(23.0)\end{array}$ & $\begin{array}{c}-0.314 \mathrm{E} 9 \\
(-45.5)\end{array}$ & -2.0 & $\begin{array}{c}0.396 \mathrm{E} 9 \\
(57.5)\end{array}$ & 2.5 \\
\hline $\begin{array}{c}\text { Inner Radius of } \\
\text { Endcap }\end{array}$ & $\begin{array}{c}0.159 \mathrm{E} 9 \\
(23.1)\end{array}$ & $\begin{array}{c}-0.458 \mathrm{E} 9 \\
(-66.4)\end{array}$ & -2.6 & $\begin{array}{c}0.396 \mathrm{E} 9 \\
(57.5)\end{array}$ & 2.5 \\
\hline
\end{tabular}

Table 4: Cyclic stresses of concern in ANSYS simulation results. Note Factors of Safety are based on endurance limits with $\mathrm{R}=-1$ and may not be accurate for lower (more negative) $R$ values. 